\title{
Ring-Opening Polymerization of Hemoglobin
}

Takashi Matsuhira, Keizo Yamamoto, Hiromi Sakai*

Department of Chemistry, Nara Medical University, 840 Shijo-cho, Kashihara, 634-8521 Japan

*Corresponding Author:

Hiromi SAKAI, Ph.D. (D. Eng.), Ph.D. (D. Med.Sci.)

Professor of Chemistry

Nara Medical University

840 Shijo-cho, Kashihara, Nara 634-8521, Japan

Tel/Fax: +81-744-29-8810

E-mail: hirosakai@naramed-u.ac.jp 


\begin{abstract}
Hemoglobin $(\mathrm{Hb})$, an oxygen-carrying protein, has an $\alpha_{2} \beta_{2}$ tetrameric structure that dissociates reversibly into two $\alpha \beta$ dimers $\left(\alpha_{2} \beta_{2} \rightleftarrows 2 \alpha \beta\right)$. We synthesized a cyclic Hb-ring monomer with two $\beta$ subunits bound through a $10 \mathrm{kDa}$ PEG chain. The monomer induced ringopening polymerization to produce a supramolecular polymer via inter-subunit interaction of $\alpha \beta$ dimers of an $\mathrm{Hb}$ molecule at the PEG terminals. Both the ring-closed monomer and the ringopened supramolecular polymer were then fixed covalently by intramolecular crosslinking of two $\beta$ subunits. Quantification of fixed products at various monomer concentrations revealed the equilibrium constant $(K)$, a ratio of propagation and depropagation rate constants, as $5.68 \mathrm{mM}^{-1}$. The average degree of polymerization $(\overline{\mathrm{DP}})$ increased proportionally, concomitantly with the initial monomer concentration. Hb polymer with $\overline{\mathrm{DP}}=13.2\left(M_{\mathrm{n}}=\right.$ ca. $\left.1 \mathrm{MDa}\right)$ was obtained by crosslinking at $2.33 \mathrm{mM}$. Our novel strategy of ring-opening polymerization of $\mathrm{Hb}$ will eventually realize a highly aligned and efficiently polymerized $\mathrm{Hb}$ for creating artificial oxygen carriers for a clinical use.
\end{abstract}

KEYWORDS: supramolecular chemistry, cyclic protein monomer, PEG modification, blood substitutes, hemoglobin-based oxygen carriers, erythrocytes 


\section{INTRODUCTION}

A supramolecular polymer is a class of polymeric arrays of monomers bound thorough non-covalent bonding such as hydrogen bonds, metal coordination bonds, host-guest interactions, and aromatic donor-acceptor interactions. ${ }^{1}$ Specific interactions between proteins such as coiled-coil interaction, heme-heme pocket interaction, and hapten-antibody complex formation are also targeted to produce supramolecular protein polymers. ${ }^{2}$ We regard such supramolecular polymerization techniques as applicable to create a hemoglobin $(\mathrm{Hb})$ polymer that will eventually be available as an artificial oxygen carrier for clinical use.

$\mathrm{Hb}$ is an oxygen-carrying protein compartmentalized in red blood cells (RBC). Many attempts have been undertaken to create artificial oxygen carriers using isolated $\mathrm{Hb}$ from $\mathrm{RBC}$. Such $\mathrm{Hb}$-based oxygen carriers (HBOCs) present several important benefits: they are pathogen free, have no blood type, and have longer shelf life than RBC. For those reasons, they are anticipated for use as RBC substitutes. ${ }^{3}$ Nevertheless, some difficulties arise when the isolated $\mathrm{Hb}$ molecules are injected into circulation. An $\mathrm{Hb}$ molecule, which consists of $\alpha_{2} \beta_{2}$ tetramer, dissociates into two $\alpha \beta$ subunits. The dimers are caught by haptoglobin and are removed from circulation immediately, thereby causing nephrotoxicity or adverse cardiovascular effects. ${ }^{4}$ Severe adverse effects such as vasoconstriction, hypertension, and oxidative stress are ascribed to the scavenging of the endothelium-derived relaxing factor, nitric oxide, by extravasation of small $\mathrm{Hb}$ molecules through the endothelial layer. ${ }^{5}$

Various approaches for chemical modification of $\mathrm{Hb}$ have been developed to resolve these difficulties. For instance, intramolecular $\alpha \alpha$ - or $\beta \beta$-crosslinked $\mathrm{Hb}^{6-8}$ inhibits dissociation of $\alpha_{2} \beta_{2}$ tetrameric structure while preventing biomolecular association with haptoglobin. ${ }^{9}$ Non- 
immunogenic polymers such as polyethylene glycol $(\mathrm{PEG})^{10,11}$ or albumin ${ }^{12}$ are conjugated to $\mathrm{Hb}$ molecules to lower antigenicity by surface covering.

The intermolecular conjugation of multiple Hbs represents a promising approach to prevent extravasation by enlarging the particle size of HBOCs. Several kinds of oligomerized or polymerized Hbs are produced by crosslinking Hbs with glutaraldehyde, ${ }^{13}$ polyamide linker, ${ }^{14,15}$ oligo- or poly-saccharides, ${ }^{16,17}$ site-specific dimerizing reagents, ${ }^{18,19}$ and bi-functional PEGs. ${ }^{20}$ In fact, glutaraldehyde-polymerized Hbs (poly-Hbs) entered clinical trials for patients, although some have already been discontinued. ${ }^{21}$ These poly-Hbs contain monomeric $\mathrm{Hb}$ or low molecular weight $\mathrm{Hb}$ oligomers. Adverse effects of vasoconstriction are expected to result from permeation of such small molecules across endothelial layer and extravasation. ${ }^{22}$ Therefore, development for realizing highly efficient polymerization of $\mathrm{Hbs}$ is now sought to improve existing poly-Hbs. Polymerized Hbs with molecular weight of tens of MDa was produced by zero-linking of $\mathrm{Hb}$ molecules. ${ }^{23}$ Other approaches to creating HBOCs without using chemical modification have also been developed. Encapsulation of $\mathrm{Hb}$ molecules in polymer membranes ${ }^{24}$ or in liposomes ${ }^{25}$ is conducted as a shield against toxicity of $\mathrm{Hb}$ molecules.

For this work, we developed an efficient polymerization procedure for creating $\mathrm{Hb}$ polymer using a novel approach: ring-opening polymerization. We earlier evaluated the exchange reaction of $\alpha \beta$ subunits between two-PEG-chains conjugated $\mathrm{Hb}$ and native $\mathrm{Hb}$ in a physiological condition. ${ }^{26}$ Based on results of that work, we designed an intramolecularly PEGbridged $\mathrm{Hb}$ as a cyclic $\mathrm{Hb}$-ring monomer (Hb-rPEG, Figure 1). For this study, Hb-rPEG was synthesized by reacting native $\mathrm{Hb}$ with a bi-functional PEG with maleimide terminals (mal ${ }_{2}-$ PEG) known to conjugate selectively to $\beta 93 \mathrm{Cys} .{ }^{27}$ During the intermolecular subunit exchange of $\alpha \beta$ dimers, $\mathrm{Hb}$-rPEG is expected to induce ring-opening polymerization to produce 
poly( $\mathrm{Hb}-\mathrm{PEG})$. It is a supramolecular polymerization using non-covalent interactions of $\alpha_{2} \beta_{2}$ tetrameric structures of $\mathrm{Hb}$ molecules as attachments. This study evaluates the existence of ringopening polymerization by colloid osmotic pressure (COP) and dynamic light scattering (DLS) measurements.

Ring-closed and ring-opened structures are fixed by reaction with bis-(3,5dibromosalicyl) fumarate (DBBF), which is known to bind two $\beta 82$ Lys through fumarate (DBBF crosslinking) ${ }^{28} \mathrm{Hb}-\mathrm{rPEG}$ was DBBF crosslinked to produce a crosslinked monomer (XL-HbrPEG) and a polymer (XL-poly(Hb-PEG)). Those products were subsequently quantified using size-exclusion chromatography (SEC). The fixed polymer, $\mathrm{XL}-$ poly(Hb-PEG), was characterized using SEC, sodium dodecyl sulfate polyacrylamide gel electrophoresis (SDSPAGE), atomic force microscopy (AFM), and DLS measurements.

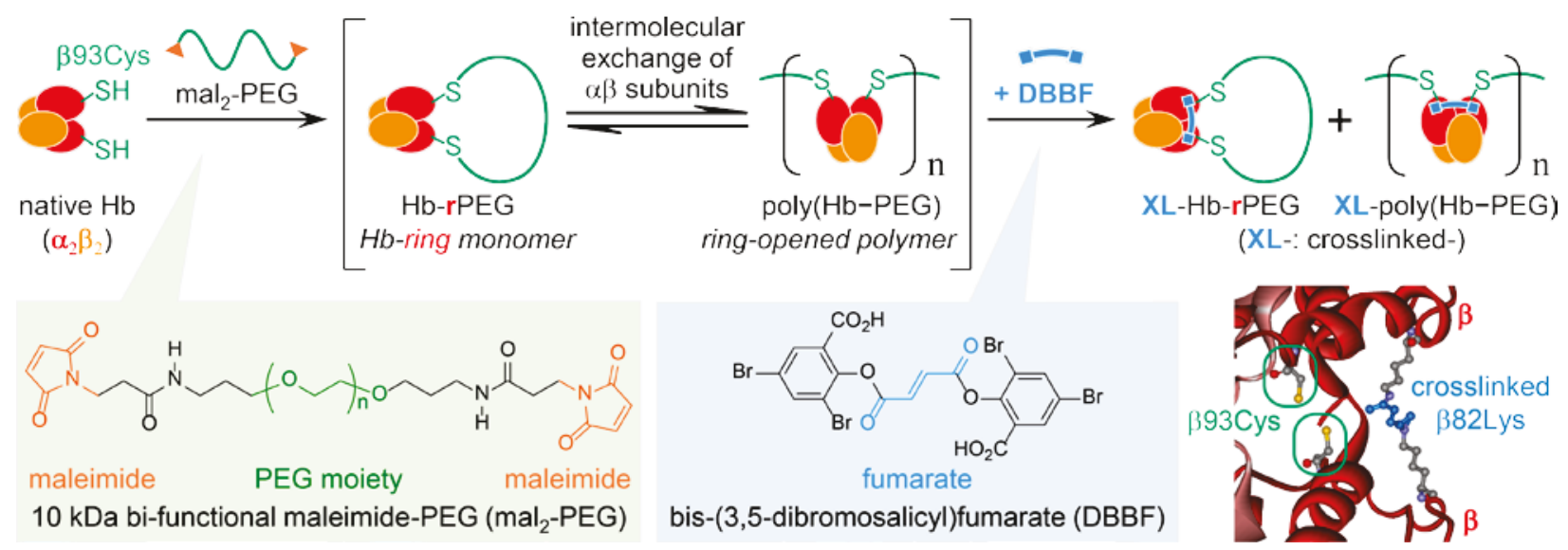

Figure 1. Ring-opening polymerization of intramolecularly PEG-bridged $\mathrm{Hb}$ as a cyclic $\mathrm{Hb}$-ring monomer (Hb-rPEG). Hb-rPEG is synthesized by reacting native $\mathrm{Hb}$ with bi-functional maleimide-PEG ( $\mathrm{mal}_{2}-\mathrm{PEG}$ ). Hb-rPEG induces ring-opening polymerization by exchanging $\alpha \beta$ subunits intermolecularly to produce poly(Hb-PEG). Ring-closed and ring-opened forms are fixed by site-selective crosslinking of two $\beta$ subunits in $\alpha_{2} \beta_{2}$ tetrameric structures using bis-(3,5- 
dibromosalicyl) fumarate (DBBF) to produce a corresponding fixed monomer and a polymer: XL-Hb-rPEG and XL-poly(Hb-PEG). The X-ray crystal structure (PDB ID: 1BIJ) of the $\mathrm{Hb}$ crosslinked by DBBF (XLHb) is shown, particularly displaying the binding sites for maleimide ( $\beta 93$ Cys) and for DBBF ( $\beta 82 \mathrm{Lys}){ }^{28}$ 


\section{MATERIALS AND METHODS}

\subsection{Materials}

Human $\mathrm{Hb}$ used for this work was purified from RBCs provided by the Japanese Red Cross. As reported elsewhere in the literature, ${ }^{29}$ a highly purified carbonyl $\mathrm{Hb}$ (native $\mathrm{Hb}$ ) solution was obtained through pasteurization and nanofiltration. DBBF crosslinked $\mathrm{Hb}$ (XLHb) was also prepared as reported in the literature. ${ }^{26,30}$ The $\mathrm{Hb}$ derivative concentrations were determined using Hemoglobin B-test Wako (Fujifilm Wako Pure Chemical Corp.).

Sodium chloride, potassium chloride, disodium hydrogen phosphate $\left(\mathrm{Na}_{2} \mathrm{HPO}_{4}\right)$, potassium dihydrogen phosphate $\left(\mathrm{KH}_{2} \mathrm{PO}_{4}\right)$, polyethylene glycol 20,000 (20 kDa PEG), ammonium sulfate, Tris(hydroxymethyl) aminomethane (Tris), sucrose, sodium dodecyl sulfate (SDS), 2-mercaptoethanol, bromophenol blue, and Coomassie brilliant blue (Quick CBB) were purchased from Fujifilm Wako Pure Chemical Corp. (Osaka, Japan). Saline (Otsuka normal saline) was purchased from Otsuka Pharmaceutical Co. Ltd. (Tokyo, Japan). Albumin (25\% human serum albumin) was purchased from Japan Blood Products Organization (Tokyo, Japan). Bi-functional maleimide PEG, mal2-PEG (Figure 1; SUNBRIGHT DE-100MA, Lot M153536, $M_{\mathrm{n}} 10456, M_{\mathrm{w}} / M_{\mathrm{n}}=1.02$, substitution 90.6\%) was purchased from NOF Corp. (Tokyo, Japan). Bis-(3,5-dibromosalicyl) fumarate (Figure 1; DBBF) was purchased from Abcam plc. (Cambridge, U.K.).

\subsection{Synthesis of Hb-ring monomer (Hb-rPEG)}


To a $31.0 \mathrm{~mL}$ of native $\mathrm{Hb}$ solution $(1.55 \mathrm{mM}, 10.0 \mathrm{~g} / \mathrm{dL}, 48.0 \mu \mathrm{mol})$ in phosphatebuffered saline (PBS, pH 7.4, $137 \mathrm{mM} \mathrm{NaCl}, 2.7 \mathrm{mM} \mathrm{KCl}, 10 \mathrm{mM} \mathrm{Na}_{2} \mathrm{HPO}_{4}$, and $1.8 \mathrm{mM}$ $\mathrm{KH}_{2} \mathrm{PO}_{4}$ ) was added 0.83 molar equivalent of powdered mal 2 -PEG (418.2 mg, $40.0 \mu \mathrm{mol}, M_{\mathrm{n}}$ 10456), followed by stirring under a $\mathrm{CO}$ atmosphere for $20 \mathrm{~h}$ at $4{ }^{\circ} \mathrm{C}$. Crude $\mathrm{Hb}$-rPEG was purified five times by salting out using $3 \mathrm{M}$ ammonium sulfate aqueous solution for native $\mathrm{Hb}$ removal. After the precipitate was dissolved in PBS, the solution was dialyzed for $20 \mathrm{~h}$ using a dialysis membrane (Size 27; Fujifilm Wako Chemicals U.S.A. Corp., Richmond, U.S.A.) against $400 \mathrm{~mL}$ PBS to remove ammonium sulfate. Then the solution was dialyzed for $4 \mathrm{~h}$ against a highly concentrated $20 \mathrm{kDa}$ PEG aqueous solution. In this procedure, water and other small molecules were withdrawn for concentration. Finally, it was dialyzed against $400 \mathrm{~mL}$ PBS for 2 h. Consequently, $10.84 \mathrm{~mL}$ Hb-rPEG solution was obtained $(2.84 \mathrm{mM},[\mathrm{Hb}]=18.3 \mathrm{~g} / \mathrm{dL}$, yield $76.7 \%)$.

\subsection{DBBF crosslinking of Hb-rPEG at different concentrations}

Concentrated Hb-rPEG solutions $(2.84 \mathrm{mM},[\mathrm{Hb}]=18.3 \mathrm{~g} / \mathrm{dL})$ with $13.2-52.9 \mu \mathrm{L}$ volume were diluted with PBS to prepare solutions having seven respective concentrations. Each solution was stirred for $8 \mathrm{~h}$ at $4{ }^{\circ} \mathrm{C}$. Subsequently, 2.0 molar equivalent DBBF was added as a suspension (10 or $20 \mathrm{mg} / \mathrm{mL}$ suspension in PBS). The final $\mathrm{Hb}$ concentrations were then adjusted to $0.04,0.08,0.16,0.31,0.62,1.55$, and $2.33 \mathrm{mM}([\mathrm{Hb}]=0.25,0.5,1.0,2.0,4.0,10.0$, and 15.0 $\mathrm{g} / \mathrm{dL}$ ). The mixtures were then stirred for $3 \mathrm{~h}$ at room temperature. Each solution was diluted with PBS to the same concentration of $0.04 \mathrm{mM}([\mathrm{Hb}]=0.25 \mathrm{~g} / \mathrm{dL})$ for SEC and SDS-PAGE analyses. 


\subsection{Synthesis of XL-poly $(H b-P E G)$}

To a $5 \mathrm{~mL}$ PBS solution of Hb-rPEG $(2.33 \mathrm{mM},[\mathrm{Hb}]=15.0 \mathrm{~g} / \mathrm{dL}, 11.6 \mu \mathrm{mol})$ was added 1.6 molar equivalent of powdered DBBF $(12.50 \mathrm{mg}, 18.6 \mu \mathrm{mol})$. It was then stirred under a CO atmosphere for $3 \mathrm{~h}$ at room temperature. The reaction mixture was filtered through a syringedriven membrane filter (DISMIC-25CS $0.45 \mu$ m cellulose acetate filter; Toyo Roshi Kaisha Ltd., Tokyo, Japan). A higher molecular weight component was fractionated using size exclusion chromatography ( $2 \mathrm{~cm}$ diameter and $30 \mathrm{~cm}$ height open column, Sepharose CL4B; SigmaAldrich Corp., St. Louis, U.S.A.). The fraction containing a higher molecular weight component was concentrated using a centrifugal filter unit (Amicon Ultra-15, $100 \mathrm{kDa}$ cutoff; Merck Millipore, Merck KGaA, U.S.A.) to obtain $0.87 \mathrm{~mL}$ of XL-poly(Hb-PEG) solution ( $0.58 \mathrm{mM}$, $[\mathrm{Hb}]=3.74 \mathrm{~g} / \mathrm{dL}$, yield $4.3 \%)$.

\subsection{Exchange of $\alpha \beta$ subunits between $H b-r P E G$ and native $H b$, and subsequent DBBF crosslinking}

After $\mathrm{Hb}$-rPEG was mixed with native $\mathrm{Hb}$ in $0.10 \mathrm{~mL}$ PBS, it was stirred for $24 \mathrm{~h}$ at $4{ }^{\circ} \mathrm{C}$. Then, 2.0 molar equivalent DBBF to total $\mathrm{Hb}$ was reacted. The final concentration of $\mathrm{Hb}-\mathrm{rPEG}$ was fixed to $1.55 \mathrm{mM}([\mathrm{Hb}]=10.0 \mathrm{~g} / \mathrm{dL})$. That of native $\mathrm{Hb}$ was adjusted to $1.55,0.62$, and 0.31 $\mathrm{mM}(10.0,4.0$, and $2.0 \mathrm{~g} / \mathrm{dL})$. For SEC analysis, each resulting solution was diluted 50 times with PBS to adjust the Hb-rPEG concentration to $0.031 \mathrm{mM}([\mathrm{Hb}]=0.20 \mathrm{~g} / \mathrm{dL})$. For comparison, 
$1.55 \mathrm{mM} \mathrm{Hb}-\mathrm{rPEG}$ solution $([\mathrm{Hb}]=10.0 \mathrm{~g} / \mathrm{dL})$ without adding native $\mathrm{Hb}$ was also reacted with DBBF.

\subsection{Intermolecular conjugation of XLHbs by mal $2-P E G$}

Preformed $0.10 \mathrm{~mL}$ XLHb solution $(3.78 \mathrm{mM}, 24.4 \mathrm{~g} / \mathrm{dL}, 0.38 \mu \mathrm{mol})$ was mixed with $0.10 \mathrm{~mL}$ mal 2 -PEG $\left(M_{\mathrm{n}} 10456\right)$ solution in PBS and was stirred for $24 \mathrm{~h}$ at $4{ }^{\circ} \mathrm{C}$. The molar ratios of XLHb to mal 2 -PEG were adjusted to 1.0 and 0.50 . Each reaction mixture contained conjugated XLHbs through PEG chains (polymerized XLHb (poly(XLHb)) and/or oligomerized $\mathrm{XLHb}$ (oligo(XLHb)). Oligo(XLHb) was fractionated using a high-performance liquid

chromatography system (HPLC, Chromaster; Hitachi High-Technologies Corp., Tokyo, Japan) equipped with a SEC column (Shodex Protein KW-804; Showa Denko K.K., Tokyo, Japan) to obtain solutions of a dimer, a trimer, a tetramer, and a pentamer.

The dumbbell-type XLHb dimer, XLHb-PEG-XLHb, was synthesized for use as a reference. To a $240 \mathrm{~mL}$ of vigorously stirred XLHb solution $(1.00 \mathrm{mM}, 6.45 \mathrm{~g} / \mathrm{dL}, 0.24 \mathrm{mmol})$ in PBS was added 0.083 molar equivalent mal $_{2}$-PEG solution $\left(M_{\mathrm{n}} 10456,209.12 \mathrm{mg}, 0.0200 \mathrm{mmol}\right.$ in $4.2 \mathrm{~mL}$ PBS) dropwise. Then, the mixture was stirred for $2 \mathrm{~h}$ under a $\mathrm{CO}$ atmosphere at room temperature, and subsequently at $4{ }^{\circ} \mathrm{C}$ for $10 \mathrm{~h}$. Excess XLHb was removed four times by salting out using $3 \mathrm{M}$ ammonium sulfate solution. After the precipitate was dissolved in PBS, the solution was dialyzed for $24 \mathrm{~h}$ using a dialysis membrane (Size 27; Fujifilm Wako Chemicals U.S.A. Corp.) against $400 \mathrm{~mL}$ saline to remove ammonium sulfate. Then it was dialyzed for $4 \mathrm{~h}$ against a highly concentrated $20 \mathrm{kDa}$ PEG aqueous solution. Finally, it was dialyzed against 400 
mL PBS for $2 \mathrm{~h}$. Consequently, 8.71 mL XLHb-PEG-XLHb solution was obtained (2.57 mM, $[\mathrm{Hb}]=16.6 \mathrm{~g} / \mathrm{dL}$, yield 56.1\%).

\subsection{Size exclusion chromatography (SEC)}

SEC was conducted using an HPLC system (Chromaster; Hitachi High-Technologies Corp.) equipped with an SEC column (Shodex Protein KW-804; Showa Denko K.K.) at 20-29 ${ }^{\circ}$ C. Effluent was monitored using a diode array detector (5430; Hitachi HighTechnologies Corp.) with absorbance at $419 \mathrm{~nm}$, which corresponds to $\lambda_{\max }$ of the Soret band of carbonyl $\mathrm{Hb}$. The modified Hbs solutions were filtered through a syringe-driven filter unit (Millex $0.22 \mu \mathrm{m}$ PVDF filter; Merck Millipore). Then $20 \mu \mathrm{L}$ of analyte was injected into the SEC column through a sampler. PBS was used as an eluent with a $1.0 \mathrm{~mL} / \mathrm{min}$ flow rate. The molecular weight of Hb-rPEG was estimated using a calibration curve obtained using three marker kits (MW-GF200 and MW-GF1000; Sigma-Aldrich Corp., and MW-Marker (HPLC); Oriental Yeast Co., Ltd., Tokyo, Japan). The molecular weight of the ring-opened polymer was estimated by extrapolation of the calibration curve obtained from small linear oligomers, up to pentamer, prepared by the reaction of preformed XLHb and mal 2 -PEG, as described in the Results section.

\subsection{Sodium dodecyl sulfate polyacrylamide gel electrophoresis (SDS-PAGE)}

All solutions of $\mathrm{Hb}$ derivative were diluted with PBS to the $\mathrm{Hb}$ concentration of 0.012 $\mathrm{mM}([\mathrm{Hb}]=0.075 \mathrm{~g} / \mathrm{dL})$. Then, each resulting solution was mixed with a half volume of the 
denaturing buffer $^{31}(0.19 \mathrm{M}$ Tris-HCl pH 6.8, 6.0\% (wt/v) SDS, 15\% (v/v) 2-mercaptoethanol, $30 \%(\mathrm{wt} / \mathrm{v})$ sucrose, and $0.006 \%(\mathrm{wt} / \mathrm{v})$ bromophenol blue) and was incubated at $80{ }^{\circ} \mathrm{C}$ for 15 $\min$.

Electrophoresis was performed on a $13 \%$ polyacrylamide mini-slab gel using a mini-slab electrophoresis system (NA-1010; Nihon Eido Corp., Tokyo, Japan), or on a gradient gel (NuPAGE 3-8\% Tris-Acetate Protein Gels; Invitrogen Corp., Thermo Fisher Scientific Inc., Waltham, U.S.A.) using a mini-slab electrophoresis system (XCell SureLock Mini-Cell; Invitrogen Corp., Thermo Fisher Scientific Inc.). An Amersham Low Molecular Weight Calibration Kit for SDS Electrophoresis (GE Healthcare Japan Ltd., Tokyo, Japan) and a HiMark Pre-Stained Protein Standard (Invitrogen Corp., Thermo Fisher Scientific Inc.) were used for molecular weight markers. After the gels were stained with Coomassie brilliant blue, images of the stained gels were obtained using transmission scanning (GT-F650; Seiko Epson Corp., Nagano, Japan).

\subsection{Colloid osmotic pressure (COP)}

COP of the Hb-rPEG was measured using a colloid osmometer (Osmomat 050; Gonotec $\mathrm{GmbH}$, Berlin, Germany) with several protein concentrations at $21-24^{\circ} \mathrm{C}$. Albumin, native $\mathrm{Hb}$, and XLHb were used as exemplary water-soluble proteins. COP $(\pi)$ is defined as shown in Eq. 1 using number-average molecular weights $\left(M_{\mathrm{n}}\right)$, the concentration of $\mathrm{Hb}$ units $(C)$, the gas constant $(R)$, the absolute temperature $(T)$, and the second and the third virial coefficients $\left(A_{2}\right.$, A3). ${ }^{32}$ 


$$
\pi=R T\left(\frac{C}{M_{\mathrm{n}}}+A_{2} C^{2}+A_{3} C^{3}+\cdots\right)
$$

Eq. 1 is converted to Eq. 2.

$$
\frac{\pi}{C}=R T\left(\frac{1}{M_{\mathrm{n}}}+A_{2} C+A_{3} C^{2}+\cdots\right)
$$

From the intercept $(\pi / C)_{C \rightarrow 0}$ of curve fitting on the plots of $\pi / C$ versus $C, 1 / M_{\mathrm{n}}$ is obtained according to Eq. 3.

$$
\frac{1}{M_{\mathrm{n}}}=\frac{1}{R T}\left(\frac{\pi}{C}\right)_{C \rightarrow 0}
$$

\subsection{Dynamic light scattering (DLS)}

The Hb-rPEG particle size distribution was measured using a particle analyzer (ELSZ2000ZS; Otsuka Electronics Co. Ltd., Osaka, Japan) equipped with a semiconductor laser ( $\lambda=$ $660 \mathrm{~nm}$ ) at $25^{\circ} \mathrm{C}$. The light-scattering signal was detected at $165^{\circ}$ (backscatter detection). The particle sizes of native $\mathrm{Hb}$ and purified $\mathrm{XL}-$ poly $(\mathrm{Hb}-\mathrm{PEG})$ were measured using a nanoparticle size analyzer (SZ-100-S; Horiba, Ltd., Tokyo, Japan) equipped with a $10 \mathrm{~mW}$ laser $(\lambda=532 \mathrm{~nm})$ at $25^{\circ} \mathrm{C}$. The light-scattering signal was detected at $173^{\circ}$ (backscatter detection). The $\mathrm{Hb}$ concentration of the Hb-rPEG solution was adjusted to $0.10,0.50,1.0,2.0$, and $4.0 \mathrm{~g} / \mathrm{dL}$ (0.015-0.62 mM), and those of native $\mathrm{Hb}$ and purified $\mathrm{XL}-$ poly $(\mathrm{Hb}-\mathrm{PEG})$ solutions were adjusted to 0.73 and $0.12 \mathrm{~g} / \mathrm{dL}(0.11$ and $0.019 \mathrm{mM})$, respectively, in PBS (pH 7.4). Before DLS measurement, each solution was filtered through a syringe-driven filter unit (Millex $0.22 \mu \mathrm{m}$ PVDF filter; Merck Millipore) to remove dust. 


\subsection{Atomic Force Microscopy (AFM)}

AFM measurement was conducted in liquid following the method reported by Tomita et al. ${ }^{33}$ with some modification (UBE Scientific Analysis Laboratory, Inc., Ube, Japan). A native $\mathrm{Hb}$ and a XL-poly(Hb-PEG) solutions in PBS were desalted using a centrifugal filter unit (100 kDa cutoff, Amicon Ultra-15; Merck Millipore) to obtain ca. $0.1 \mathrm{~g} / \mathrm{dL}$ solution in distilled water. Each solution was diluted $10^{3}$ times with ultrapure water. Then the native $\mathrm{Hb}$ and the XLpoly $(\mathrm{Hb}-\mathrm{PEG})$ molecules were fixed on a mica plate. Microscopic images were obtained using atomic force microscopy (MultiMode 8; Bruker Corp., Santa Barbara, U.S.A.) with a control system (Nanoscope V; Bruker Corp.) using a $\mathrm{Si}_{3} \mathrm{~N}_{4}$ cantilever. The measurement was conducted in ultrapure water at room temperature. The spring constant was $0.7 \mathrm{~N} / \mathrm{m}$, and the scanning resolution was 512 pixels versus 512 lines. 


\section{RESULTS}

\subsection{Synthesis and characterization of Hb-rPEG}

Hb-rPEG was identified using SEC and SDS-PAGE. In the SEC profile, Hb-rPEG was observed as a narrow peak at 10.89 min, indicating larger size than native Hb (Figure 2A). The molecular weight of $\mathrm{Hb}$-rPEG was found to be $98 \mathrm{kDa}$ by comparison with molecular weight marker proteins for SEC.

SDS-PAGE analysis clarified that free $\alpha$ subunits remained in Hb-rPEG (Figure 2B). The band of free $\beta$ subunit disappeared at Hb-rPEG. Instead, a band $\boldsymbol{a}$ ascribed to two $\beta$ subunits linked with PEG ( $\beta-\mathrm{PEG}-\beta)$ appeared. Band $\boldsymbol{a}$ was observed near the $45 \mathrm{kDa}$ marker, which coincided to the expected molecular weight $(42.2 \mathrm{kDa})$. These results indicate site-selective conjugation between mal $_{2}-\mathrm{PEG}$ and two $\beta$ subunits ( $\left.\beta 93 \mathrm{Cys}\right)$ of an $\mathrm{Hb}$ molecule. ${ }^{34}$
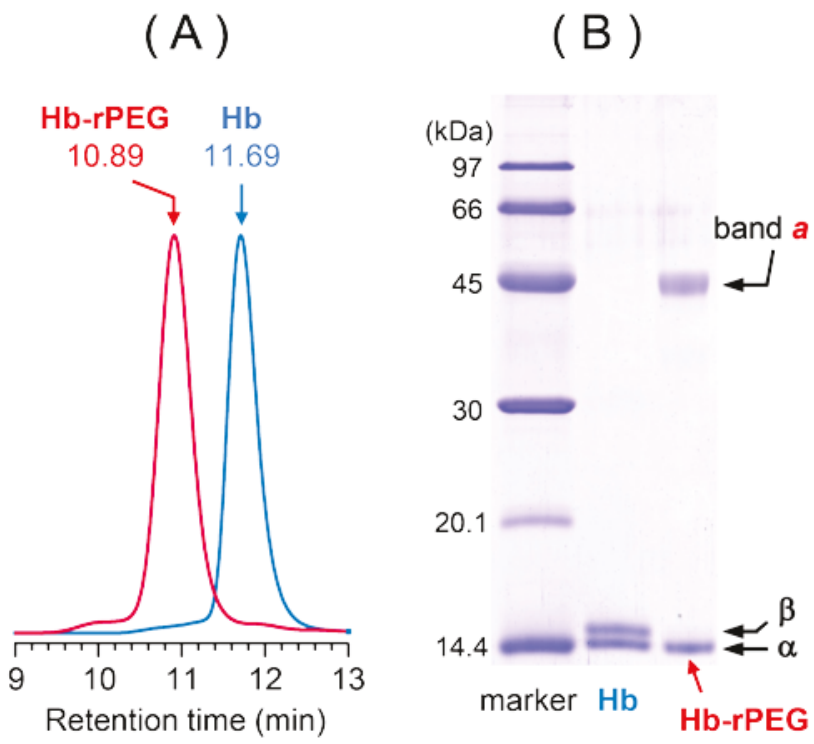

Figure 2. (A) SEC profiles of $\mathrm{Hb}$-rPEG and native $\mathrm{Hb}$. Both $\mathrm{Hb}-\mathrm{rPEG}$ and native $\mathrm{Hb}$ are observed as narrow peaks. (B) SDS-PAGE analysis of native $\mathrm{Hb}$ and $\mathrm{Hb}-\mathrm{rPEG}$. One $\mathrm{Hb}$ 
molecule consists of two $\alpha(15.1 \mathrm{kDa})$ and two $\beta(15.9 \mathrm{kDa})$ subunits. One Hb-rPEG molecule consists of two $\alpha$ subunits and one PEG-linked two- $\beta$ subunit (band $\mathbf{a}, \beta-\mathrm{PEG}-\beta, 42.2 \mathrm{kDa}$ ).

\subsection{Concentration-dependence of Hb-rPEG size by COP and DLS measurements}

The colloid osmotic pressure (COP, $\pi$ ) of Hb-rPEG solution increases with the concentration of $\mathrm{Hb}$ units $(C)$, similarly to native $\mathrm{Hb}$ (Figure 3A). Plots of $\pi / C$ versus $C$ of $\mathrm{Hb}$ rPEG showed a parabolic curve (red line), whereas those of some representative water soluble proteins, such as human serum albumin (green line), XLHb (purple line), and native $\mathrm{Hb}$ (blue line), showed linear relations (Figure 3B). The number average molecular weight $\left(M_{\mathrm{n}}\right)$ of $\mathrm{Hb}$ rPEG was found to be $104 \mathrm{kDa}$ from the intercept of the quadric curve fitting (Supporting Information Table S1). The value is regarded as reflecting the molecular size in an infinitely diluted condition. It almost coincides with that ascertained from SEC analysis (98 kDa). Dynamic light scattering (DLS) of Hb-rPEG showed an inconsistent size distribution depending on the concentration (Figure 4). The particle diameter of Hb-rPEG was $10.6 \pm 3.6 \mathrm{~nm}$ at $[\mathrm{Hb}]=$ $0.10 \mathrm{~g} / \mathrm{dL}$. It increased with the concentration to reach $20.4 \pm 13.7 \mathrm{~nm}$ at $[\mathrm{Hb}]=4.0 \mathrm{~g} / \mathrm{dL}$. The polydispersity index also increased with the concentration, indicating that the size distribution tends to become broader at a higher concentration (Supporting information Table S2). 

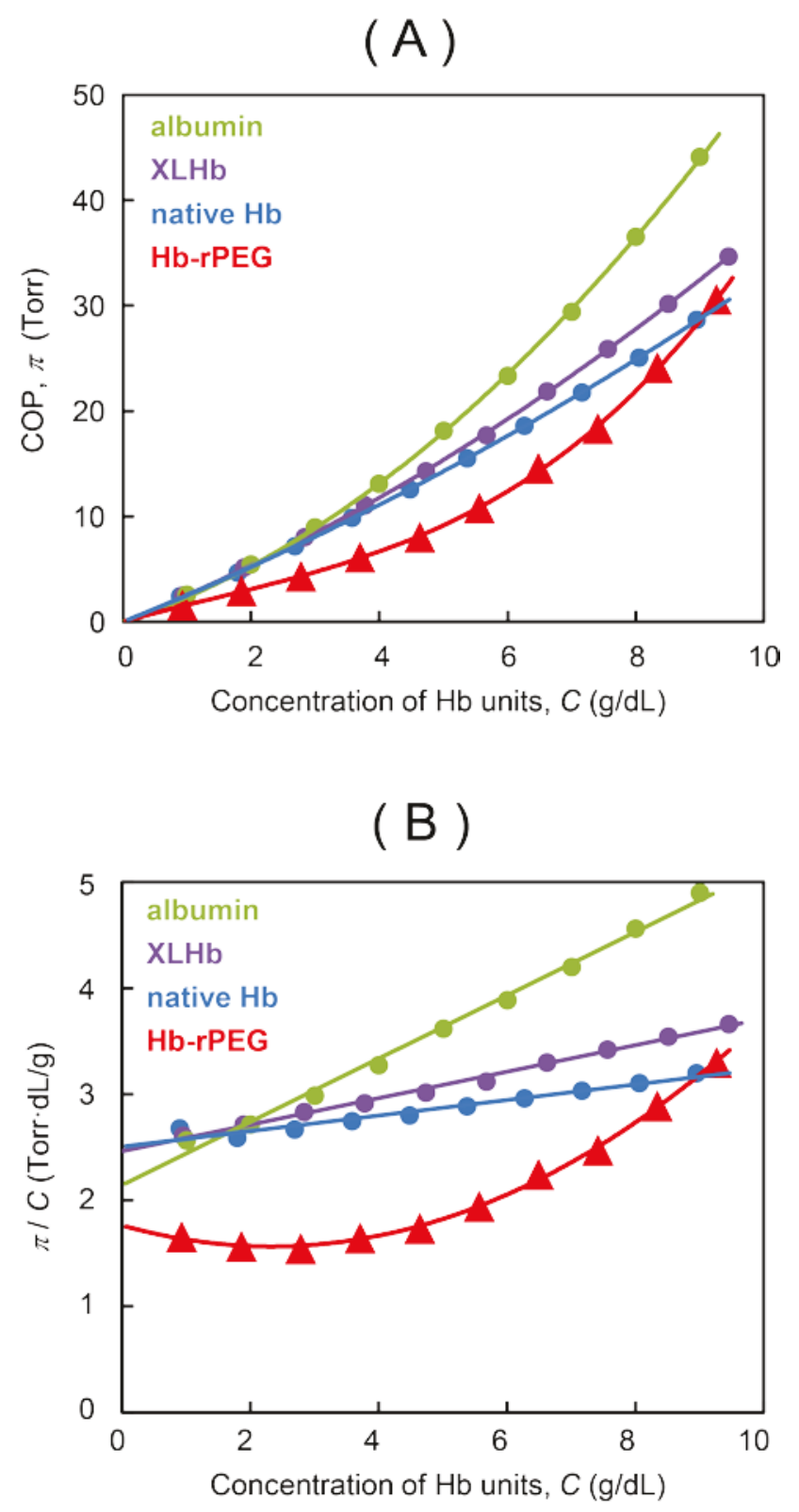

Figure 3. (A) Colloid osmotic pressure (COP, $\pi$ ) of $\mathrm{Hb}$-rPEG (red line) as a function of the concentration of $\mathrm{Hb}$ units $C$, with representative water soluble proteins of human serum albumin (green line), XLHb (purple line), and native $\mathrm{Hb}$ (blue line). (B) Plots of $\pi / C$ versus $C$. Only $\mathrm{Hb}-$ rPEG showed a parabolic curve, whereas others showed linear relations. 


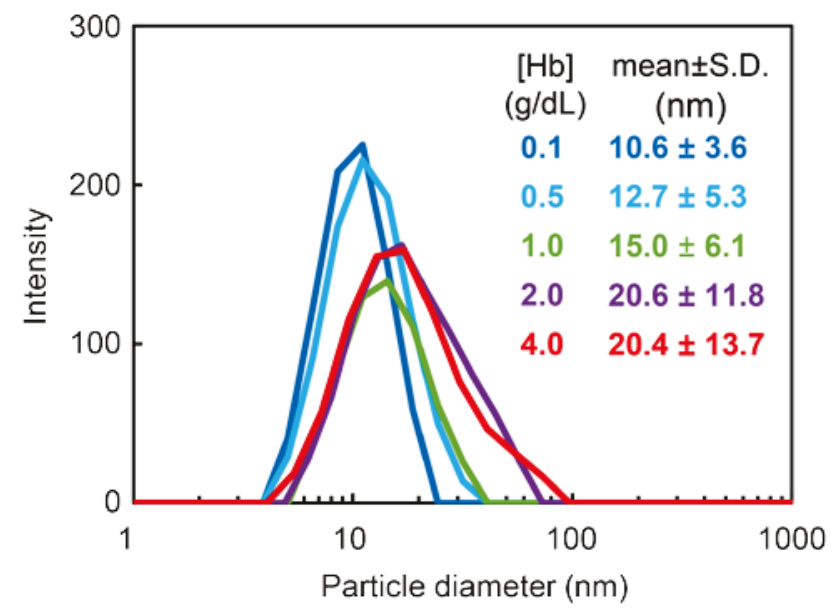

Figure 4. Particle size distribution of Hb-rPEG obtained using dynamic light scattering (DLS) measurements for different concentrations of $\mathrm{Hb}$ units of $0.10-4.0 \mathrm{~g} / \mathrm{dL}$. The average size and the standard deviation (S.D.) at each concentration are shown in the graph.

\subsection{Fixing $\alpha_{2} \beta_{2}$ tetrameric structures of ring-opened and ring-closed Hb-rPEGs by DBBF crosslinking}

DBBF crosslinking was used to fix $\alpha_{2} \beta_{2}$ tetrameric structures that reflect the equilibrated state of ring-opening and ring-closing reactions for Hb-rPEG (Figure 1). After the Hb-rPEG concentration was adjusted to various concentrations of $0.04-2.33 \mathrm{mM}([\mathrm{Hb}]=0.25-15 \mathrm{~g} / \mathrm{dL})$, the $\alpha_{2} \beta_{2}$ structures were fixed by DBBF crosslinking. The crosslinked products were analyzed using SEC (Figure 5). When reacting with DBBF at a low concentration of $0.04 \mathrm{mM}$ (blue line), the cyclic monomer (Hb-rPEG) remained as the corresponding ring-closed monomeric XLHb (XL-Hb-rPEG) at 10.91 min, showing almost equal retention time of non-crosslinked Hb-rPEG (10.89 $\mathrm{min})$. The ratio of monomeric XL-Hb-rPEG decreased concomitantly with increasing 
concentration of DBBF crosslinking. As inferred from the decrease of the peak area of XL-HbrPEG, nearly half of the cyclic monomers turned to the opened form at $0.31 \mathrm{mM}$ (purple line). A broad peak ascribed to the fixed ring-opened polymers (XL-poly(Hb-PEG)) was observed at $7.51 \mathrm{~min}$. The retention time is much shorter than that of $669 \mathrm{kDa}$ thyroglobulin $(8.78 \mathrm{~min})$. The peak of XL-poly(Hb-PEG) shifted to shorter retention times with increasing the monomer concentration. The high molecular weight component $(6.45 \mathrm{~min})$ increased when crosslinked at a high $\mathrm{Hb}$ concentration of $2.33 \mathrm{mM}$ (red line).

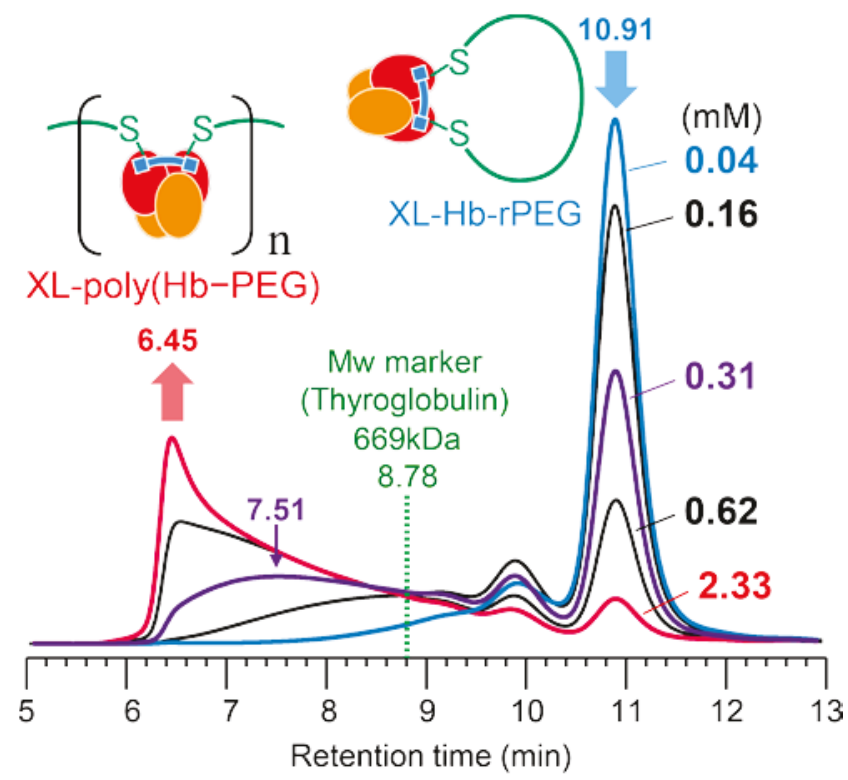

Figure 5. SEC profiles obtained for products of reacting Hb-rPEG with DBBF at different monomer concentrations of $0.04,0.16,0.31,0.62$, and $2.33 \mathrm{mM}([\mathrm{Hb}]=0.25,1.0,2.0,4.0$, and $15 \mathrm{~g} / \mathrm{dL}$ ). After DBBF crosslinking, each reaction mixture was diluted to the same concentration of $0.04 \mathrm{mM}([\mathrm{Hb}]=0.25 \mathrm{~g} / \mathrm{dL})$. Each was then analyzed. 
Products obtained by reacting Hb-rPEG with DBBF at different concentrations of 0.04, 0.31 , and $2.33 \mathrm{mM}([\mathrm{Hb}]=0.25,2.0$, and $15 \mathrm{~g} / \mathrm{dL})$ were analyzed using SDS-PAGE (Figure 6). Band $\boldsymbol{a}$ of $\beta-\mathrm{PEG}-\beta$, one component of Hb-rPEG, disappeared by DBBF crosslinking at 0.04 $\mathrm{mM}$. Alternatively, a new band $\boldsymbol{b}$ with a lower mobility than band $\boldsymbol{a}$ appeared. The new band $\boldsymbol{b}$ was assigned as the PEGylated $\beta-\beta$ component with a closed ring structure ( $\beta-\beta-$-ringPEG), which is one component of XL-Hb-rPEG. Both $\beta-\mathrm{PEG}-\beta$ and $\beta-\beta-$ ringPEG are expected to have equal molecular weight $(42.2 \mathrm{kDa})$, but because of their different morphologies, they showed different mobility in the polyacrylamide gel. In contrast to the diluted condition, a polymeric component (poly( $\beta-\beta-\mathrm{PEG})$ ) was observed as band $\boldsymbol{c}$ by DBBF crosslinking of $\mathrm{Hb}$ rPEG at a higher concentration of $2.33 \mathrm{mM}$. When crosslinked at $0.31 \mathrm{mM}$, both bands $\boldsymbol{b}$ and $\boldsymbol{c}$ were observed at almost equal intensity, which supported the SEC result (Figure 5). Free $\alpha$ subunits remained after crosslinking at every concentration, indicating that DBBF crosslinks PEGylated $\beta$ subunits selectively in the same manner as that of native $\mathrm{Hb}^{26}$ 


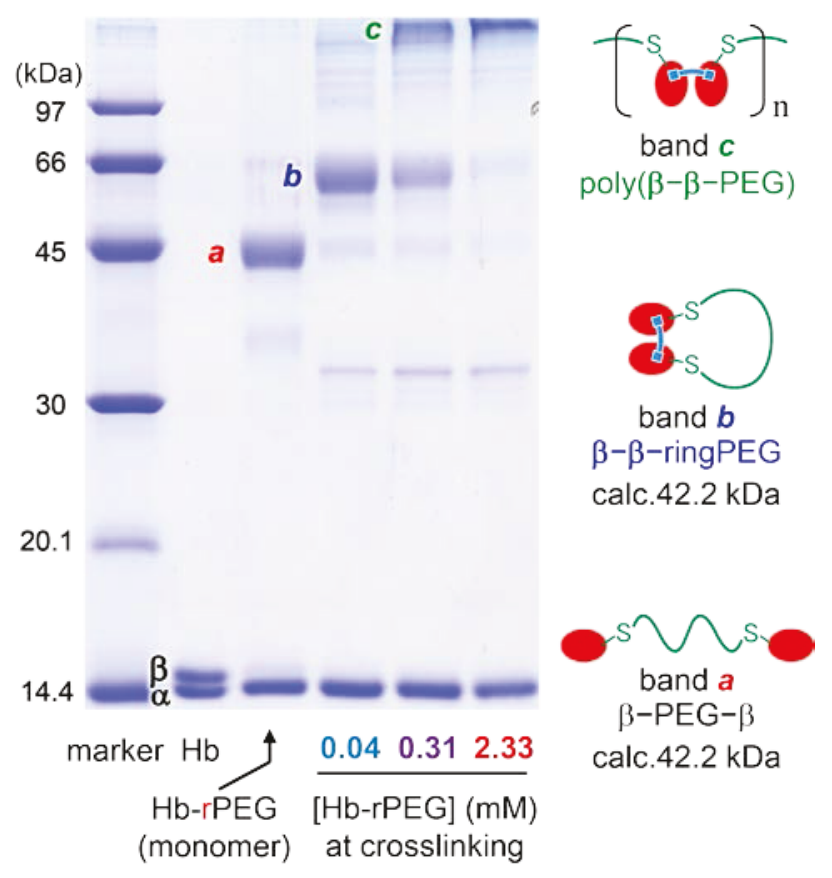

Figure 6. SDS-PAGE of the DBBF crosslinked Hb-rPEG at different concentrations of 0.04, 0.31 , and $2.33 \mathrm{mM}([\mathrm{Hb}]=0.25,2.0$, and $15.0 \mathrm{~g} / \mathrm{dL})$. A band $\boldsymbol{a}$ ascribed to $\beta-\mathrm{PEG}-\beta$ observed in Hb-rPEG disappeared by DBBF crosslinking. Instead, a band $\boldsymbol{b}$ of the PEGylated $\beta-\beta$ component with a closed ring structure ( $\beta-\beta-$-ringPEG), and a band $\boldsymbol{c}$ of the polymeric component (poly( $\beta-\beta-\mathrm{PEG}))$ were observed. Band $\boldsymbol{b}$ was observed preferentially at a lower crosslinking concentration of $0.04 \mathrm{mM}$. Band $\boldsymbol{c}$ was observed preferentially at a higher crosslinking concentration of $2.33 \mathrm{mM}$. Both bands $\boldsymbol{b}$ and $\boldsymbol{c}$ were observed at a crosslinking concentration of $0.31 \mathrm{mM}$.

\subsection{Ring-opening polymerization of Hb-rPEG versus stepwise XLHb conjugation by mal $_{2}-$} PEG 
The SEC profile of the reaction products of $\mathrm{Hb}-\mathrm{rPEG}$ and DBBF at $\mathrm{Hb}$ concentration of $10 \mathrm{~g} / \mathrm{dL}(1.55 \mathrm{mM})$ is shown in Figure 7A. As ring-opening polymerization proceeded, the fixed polymer, XL-poly(Hb-PEG), was observed at 6.47 min with 10.9\% monomeric XL-Hb-rPEG remaining at $10.94 \mathrm{~min}$. The size of the ring-opened product gradually decreased concomitantly with increasing concentration of native $\mathrm{Hb}$ from 2.0 to $10.0 \mathrm{~g} / \mathrm{dL}$ (Figures $7 \mathbf{B}, 7 \mathbf{C}$, and 7D). In these chromatograms, discontinuous peaks of a crosslinked dimer, a trimer, a tetramer, and a pentamer were observed respectively at ca. 10.0, 9.1, 8.5, and 8.1 min. Monomeric $\mathrm{Hbs}(\mathrm{Hb}-$ rPEG and native $\mathrm{Hb}$ ) were also DBBF crosslinked to generate XL-Hb-rPEG and XLHb, and were observed respectively at 10.9 and $11.6 \mathrm{~min}$. No oligomers were found before reacting with DBBF (Supporting information Figure S1), indicating that the production of such oligomers depends strongly on the concentration, and it is difficult to detect them by SEC without crosslinking.

For comparison, preformed XLHb molecules were conjugated by 1.0 or 0.50 equivalent molar mal 2 -PEG (Figures $7 \mathbf{E}$ and $7 \mathbf{F}$ ). In the case of the 1.0 equivalent molar reaction, polymerized XLHb (poly(XLHb)) was observed at $6.45 \mathrm{~min}$, with smaller oligomers (9.20 and $9.99 \mathrm{~min})$ and unreacted XLHb (11.65 $\mathrm{min})$. In the case of reaction of XLHb with 0.50 equivalent molar mal $_{2}-\mathrm{PEG}$, the SEC profile of the products (Figure 7F) showed a similar profile to that shown in Figure 7D. This result demonstrates that the products of oligomeric $\mathrm{XLHb}$ obtained by reacting with bi-functional PEG were identical to those of subunit exchange between native $\mathrm{Hb}$ and $\mathrm{Hb}$-rPEG, followed by DBBF crosslinking.

Each product observed in Figure 7F at 10.05, 9.18, 8.59, and 8.06 min was fractionated and then analyzed again using SEC (Figure 7G). As a reference, the XLHb dimer (XLHb-PEG-XLHb) was synthesized by reacting excess XLHb with mal2-PEG (Figure 7H). 
The profiles of blue chromatograms of Figures $\mathbf{7 G}$ and $\mathbf{7 H}$ coincided, indicating that the peak at $10.05 \mathrm{~min}$ is ascribable to a dumbbell dimer: $\mathrm{XLHb}-\mathrm{PEG}-\mathrm{XLHb}$. SDS-PAGE analysis of the fractions in Figure 7G clarified that the peak of $9.17 \mathrm{~min}$ is a trimer, and those of 8.53 and 8.11 min are inferred to be a tetramer and a pentamer, respectively (Supporting Information Figure S2).

The relation between the retention time and the molecular weights of these oligomers and $\mathrm{XLHb}$ is shown as a blue line on a logarithmic scale in Figure 8. They are on a linear fit $\left(r^{2}>0.999\right)$, and are applicable to produce a calibration curve for XL-poly $(\mathrm{Hb}-\mathrm{PEG})$. The green line in the figure represents a calibration curve obtained from globular proteins. The slope of the green line is steeper than that of the blue line, indicating that PEG moiety provides large hydrodynamic volume to the globular proteins. The molecular weights of the ring-opened products, $\mathrm{XL}-$ poly $(\mathrm{Hb}-\mathrm{PEG})$, observed in Figure 5 were estimated by extrapolation of this blue line. The molecular weight of XL-poly(Hb-PEG) was controlled in the wide range of 218-812 $\mathrm{kDa}$ by regulating the initial monomer concentration of $0.16-2.33 \mathrm{mM}$ (Supporting information Table S3). The molecular weight of XL-poly(Hb-PEG) observed in Figure 7A (6.47 min) was estimated as $804 \mathrm{kDa}$, which corresponded to an undecamer (11 mer). Figures 5, 7A, and 7E show that the peak of the polymer appeared abruptly at $6.2 \mathrm{~min}$. The polymer size almost reaches the void volume, and it is the detection limit of the column (protein KW804). Therefore, the actual molecular weight of XL-poly(Hb-PEG) might be larger than that estimated from the calibration curve. 

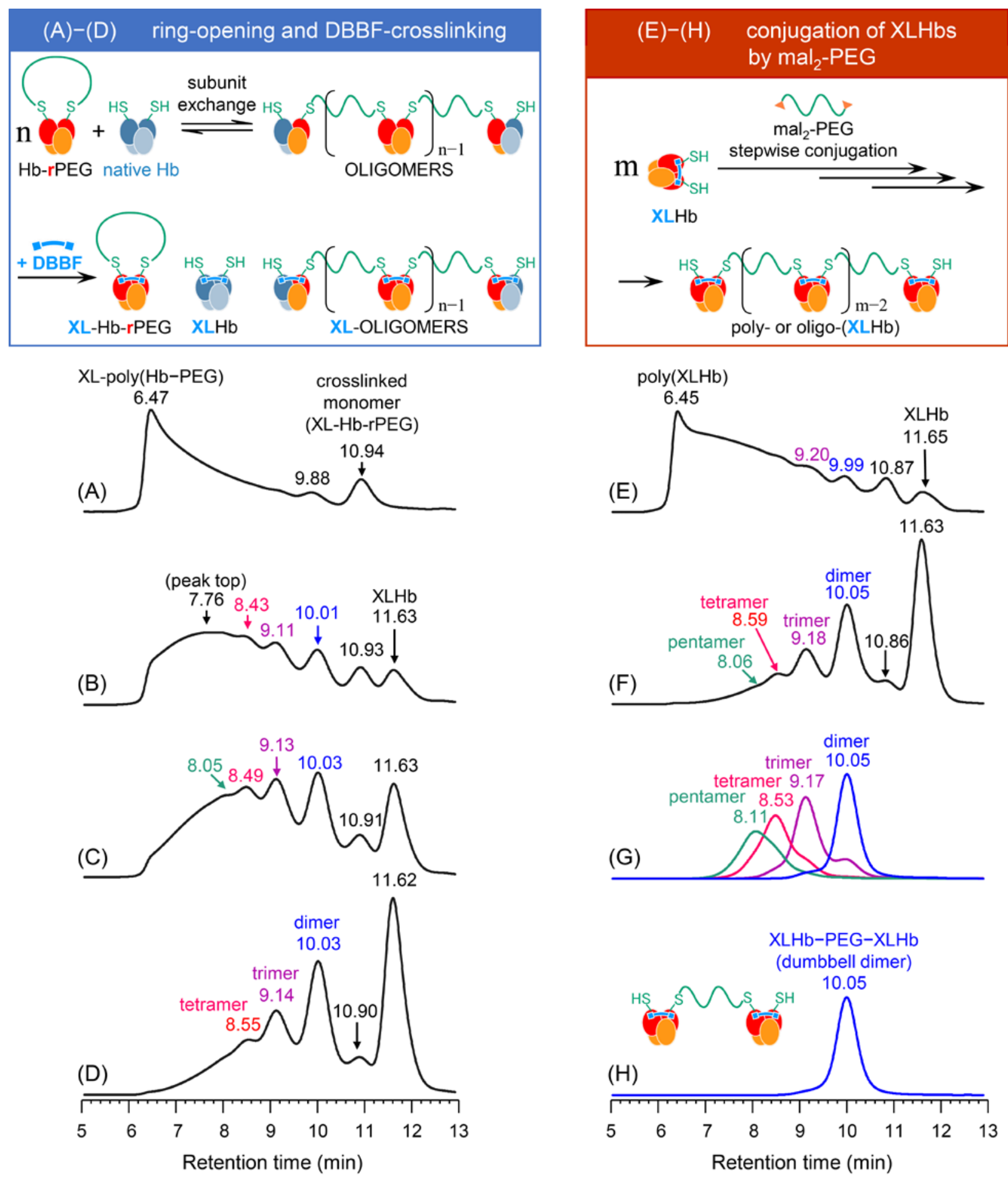

Figure 7. Comparison of SEC profiles of ring-opening and subsequent DBBF crosslinked products in the presence of different amount of native $\mathrm{Hb}$ (left panels, (A)-(D)), and intermolecularly conjugated XLHbs by mal 2 -PEG (right panels, (E)-(H)). (A) $0 \mathrm{~g} / \mathrm{dL}$ (no native 
$\mathrm{Hb}$ ), (B) $2.0 \mathrm{~g} / \mathrm{dL},(\mathrm{C}) 4.0 \mathrm{~g} / \mathrm{dL}$, and (D) $10.0 \mathrm{~g} / \mathrm{dL}$ native $\mathrm{Hb}$ was mixed with $10.0 \mathrm{~g} / \mathrm{dL} \mathrm{Hb}-$ rPEG, and then DBBF was reacted to each mixture. The preformed XLHb was reacted (E) with equimolar mal $_{2}$-PEG and (F) with 0.50 equimolar mal 2 -PEG. (G) Fractionated products of XLHb and 0.50 equimolar mal $_{2}$-PEG: a dimer (blue), a trimer (purple), a tetramer (pink), and a pentamer (green). (H) Dumbbell-type XLHb dimer, XLHb-PEG-XLHb, for reference.

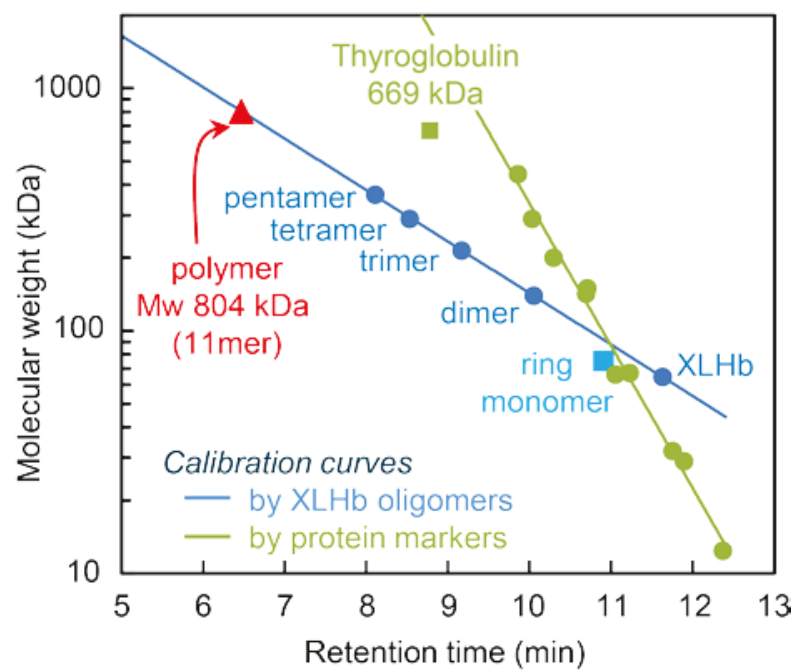

Figure 8. Calibration curves obtained by retention times $(t)$ of fractionated XLHb oligomers as shown in Figure 7F (blue line, $\log M_{\mathrm{n}}=-0.2124 t+4.2794, r^{2}=0.9998$ ), and that obtained using protein markers except for thyroglobulin (green line, $\log M_{\mathrm{n}}=-0.5875 t+8.4000, r^{2}=0.9889$ ). The molecular weight of the ring-opened and subsequently fixed polymer, as shown in Figure 7A, was estimated by extrapolation as $804 \mathrm{kDa}$. 


\subsection{Kinetic analysis of ring-opening polymerization equilibrium of $\mathrm{Hb}-\mathrm{rPEG}$}

The ring-opening polymerization mechanism of $\mathrm{Hb}-\mathrm{rPEG}$ is regarded as similar to that of low molecular weight organic compounds such as lactone, lactam, cycloalkene, and cyclic ether. ${ }^{35}$ Reactions of propagation and depropagation proceed simultaneously. They are expected to be in an equilibrated state (Scheme 1).

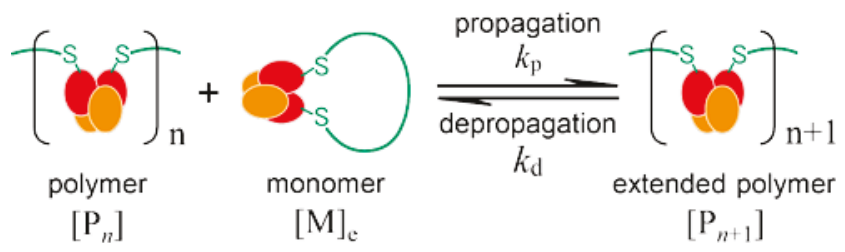

Scheme 1. Ring-opening polymerization equilibrium of Hb-rPEG.

The equilibrium in Scheme 1 can be described as Eq. 4.

$$
\mathrm{P}_{n}+\mathrm{M} \rightleftarrows \mathrm{P}_{n+1}
$$

The equilibrium constant, $K$, which is the ratio of polymerization $\left(k_{\mathrm{p}}\right)$ and depolymerization $\left(k_{\mathrm{d}}\right)$ rate constants, is defined by Eq. 5 using the concentrations of a polymer and a one unit extended polymer $\left[\mathrm{P}_{n}\right]$ and $\left[\mathrm{P}_{n+1}\right]$, and the equilibrium monomer concentration $[\mathrm{M}]_{\mathrm{e}}$.

$$
K=\frac{k_{\mathrm{p}}}{k_{\mathrm{d}}}=\frac{\left[\mathrm{P}_{n+1}\right]}{\left[\mathrm{P}_{n}\right][\mathrm{M}]_{\mathrm{e}}}
$$

When the polymer is sufficiently long, $\left[\mathrm{P}_{n}\right]$ and $\left[\mathrm{P}_{n+1}\right]$ become nearly identical. Therefore, $K$ is obtained as a reciprocal of $[\mathrm{M}]_{\mathrm{e}}$ as shown in Eq. . $^{35}$ 


$$
K \approx{\frac{1}{[\mathrm{M}]_{\mathrm{e}}}}_{(n \gg \gg 1)}
$$

Hb-rPEG was reacted with DBBF at various initial monomer concentrations $\left([\mathrm{M}]_{0}=0.04,0.08\right.$, $0.16,0.31,0.62,1.55$, and $2.33 \mathrm{mM})$. Then, each solution was diluted to the same concentration $(0.04 \mathrm{mM})$. The products were analyzed using SEC as shown in Figure 5. The amount of XLHb-rPEG was quantified from the peak area at 12.91 min (Supporting information Table S4). The remaining ratio of cyclic monomer at the equilibrium state is regarded to correspond to that of DBBF crosslinked one: XL-Hb-rPEG. Actually, the equilibrium monomer concentration $[\mathrm{M}]_{\mathrm{e}}$, was obtained from the product of the $[\mathrm{M}]_{0}$ and the remaining ratio of the cyclic monomer.

The relation between $1 /[\mathrm{M}]_{\mathrm{e}}$ and $[\mathrm{M}]_{0}$ is presented in Figure 9. The value of $1 /[\mathrm{M}]_{\mathrm{e}}$ declines at a lower $[\mathrm{M}]_{0}$; it becomes constant at a higher $[\mathrm{M}]_{0}$. From the average of $1 /[\mathrm{M}]_{\mathrm{e}}$ at higher concentrations $\left([\mathrm{M}]_{0}=0.31,0.62,1.55\right.$, and $\left.2.33 \mathrm{mM}\right)$, the $K$ value was found to be 5.68 $\mathrm{mM}^{-1}$. The corresponding $[\mathrm{M}]_{\mathrm{e}}$ was $0.176 \mathrm{mM}([\mathrm{Hb}]=1.14 \mathrm{~g} / \mathrm{dL})$. From $[\mathrm{M}]_{\mathrm{e}}$, the ratio of the monomer reacted $(P)$ is defined as Eq. 7.

$$
P=\frac{[\mathrm{M}]_{0}-[\mathrm{M}]_{\mathrm{e}}}{[\mathrm{M}]_{0}}
$$

The number average degree of polymerization $(\overline{\mathrm{DP}})$ defined using $P$ is converted to the ratio of $[\mathrm{M}]_{0}$ to $[\mathrm{M}]_{\mathrm{e}}$ as Eq. $\mathbf{8}^{36}$

$$
\overline{\mathrm{DP}}=\frac{1}{1-P}=\frac{[\mathrm{M}]_{0}}{[\mathrm{M}]_{\mathrm{e}}}
$$

The relation between estimated $\overline{\mathrm{DP}}$ and $[\mathrm{M}]_{0}$ is shown in the inset of Figure 9. As shown there, $\overline{\mathrm{DP}}$ increases proportionally with $[\mathrm{M}]_{0}$. The estimated molecular weight reaches nearly $1 \mathrm{MDa}$ 
$(990 \mathrm{kDa})$ at $[\mathrm{M}]_{0}=2.33 \mathrm{mM}([\mathrm{Hb}]=15 \mathrm{~g} / \mathrm{dL})$. That value roughly matches the result obtained from SEC $(>800 \mathrm{kDa})$.

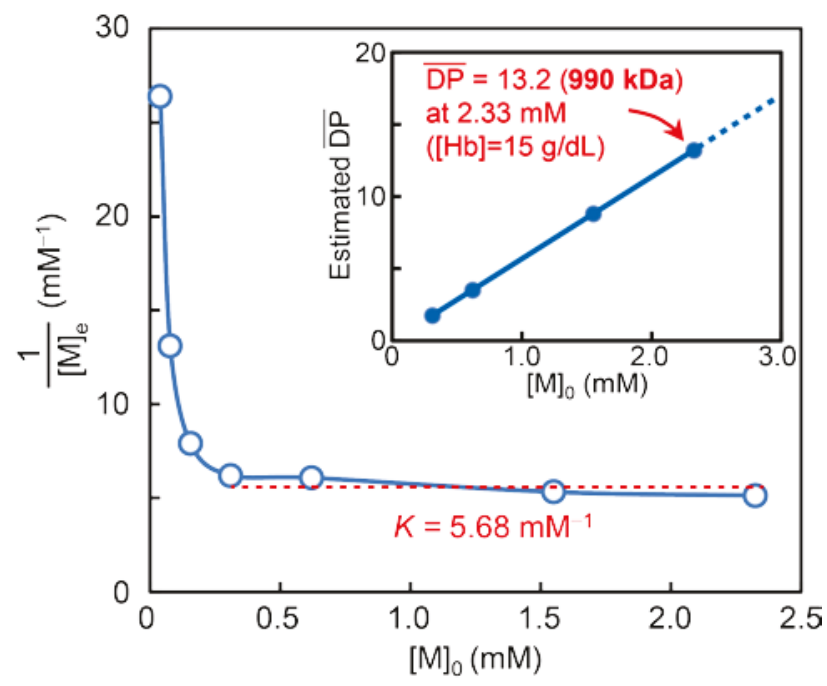

Figure 9. Relation between $1 /[\mathrm{M}]_{\mathrm{e}}$ and $[\mathrm{M}]_{0}$, where $[\mathrm{M}]_{\mathrm{e}}$ is a monomer concentration at the equilibrium state and $[\mathrm{M}]_{0}$ is the initial monomer concentration. $[\mathrm{M}]_{\mathrm{e}}$ was quantified from the peak area of XL-Hb-rPEG in SEC analysis (Supporting Information Table S4). Using Eq. 6, the $K$ value was found to be $5.68 \mathrm{mM}^{-1}$ from the average of $1 /[\mathrm{M}]_{\mathrm{e}}$ at $[\mathrm{M}]_{0}=0.31,0.62,1.55$, and $2.33 \mathrm{mM}$. The inset graph shows the relation between estimated $\overline{\mathrm{DP}}$ and $[\mathrm{M}]_{0}$, where $\overline{\mathrm{DP}}$ is the number average degree of polymerization obtained from Eq. 8.

\subsection{Purification and characterization of ring-opened and fixed polymer $X L-p o l y(H b-P E G)$}

The $\mathrm{Hb}$ concentration of $\mathrm{Hb}-\mathrm{rPEG}$ was adjusted to $2.33 \mathrm{mM}([\mathrm{Hb}]=15.0 \mathrm{~g} / \mathrm{dL})$. Then DBBF was reacted. At this concentration, $\mathrm{Hb}-\mathrm{rPEG}$ forms the corresponding supramolecular 
polymer (poly(Hb-PEG)) conjugated through non-covalent intermolecular binding. The $\alpha_{2} \beta_{2}$ tetrameric structures in poly $(\mathrm{Hb}-\mathrm{PEG})$ were fixed using $\mathrm{DBBF}$ crosslinking. Then the fixed polymer XL-poly(Hb-PEG) with the higher molecular weight was fractionated using an open column SEC. The SEC profiles and SDS-PAGE images before and after purification are presented for comparison in Figure 10. Monomeric structure was observed after DBBF crosslinking as a peak at $10.91 \mathrm{~min}$ (XL-Hb-rPEG) in chromatogram $\mathbf{I}$, and as bands $\boldsymbol{b}$ $(\beta-\beta-$ ringPEG) in lanes I. They disappeared after purification (chromatogram II and lane II). The retention time of the peak top in Figure 10A becomes shorter by purification from 6.45 to $6.37 \mathrm{~min}$, indicating the higher molecular weight distribution after purification. The molecular weights of $\mathrm{XL}-$ poly(Hb-PEG) before and after purification were estimated respectively as 812 and $844 \mathrm{kDa}$ by extrapolation of the calibration curve in Figure 8.

The result of 13\% SDS-PAGE (Figure 10B, left, lane II) shows that purified XLpoly $(\mathrm{Hb}-\mathrm{PEG})$ consists of free $\alpha$ subunits and polymeric $\beta-\beta$ components (poly $(\beta-\beta-\mathrm{PEG})$, bands $\boldsymbol{d}$ ). When we specifically examine the higher molecular weight region in SDS-PAGE using a 3-8\% gradient gel (Figure 10B, right), bands $\boldsymbol{C}$ and bands $\boldsymbol{d}$ ascribed to poly $(\beta-\beta-\mathrm{PEG})$ are observed as ladder bands, indicating the discontinuous distribution of molecular weight for $\mathrm{XL}$-poly(Hb-PEG). The molecular weight distribution of poly $(\beta-\beta-\mathrm{PEG})$ observed as bands $\boldsymbol{d}$ in lane II is higher than that of bands $\boldsymbol{c}$ in lane $\mathbf{I}$, which coincides with the SEC result. Bands $\boldsymbol{d}$ are observed mainly around the $460 \mathrm{kDa}$ marker, indicating that the molecular weight of the corresponding XL-poly(Hb-PEG) is nearly $800 \mathrm{kDa}$.

The structure of purified XL-poly(Hb-PEG) was confirmed directly using atomic force microscopy (AFM). $\mathrm{Hb}$ molecules constituting XL-poly(Hb-PEG) were localized, whereas native $\mathrm{Hb}$ molecules were dispersed uniformly on the mica plate (Figure 11A). This result 
indicates the existence of the conjugated $\mathrm{Hb}$ polymer. The height of each $\mathrm{Hb}$ molecule consisting $\mathrm{XL}-$ poly $(\mathrm{Hb}-\mathrm{PEG}$ ) was ca. $2-3 \mathrm{~nm}$, which is similar to that of native $\mathrm{Hb}$ (Supporting information Figure S3). Around $10 \mathrm{Hb}$ molecules were conjugated to form 50-80 nm diameter particles. The particle diameter of the purified XL-poly(Hb-PEG) was also estimated as $97 \pm 45$ nm by DLS measurement (Figure 11B). That value roughly coincides with the size observed in AFM image. 

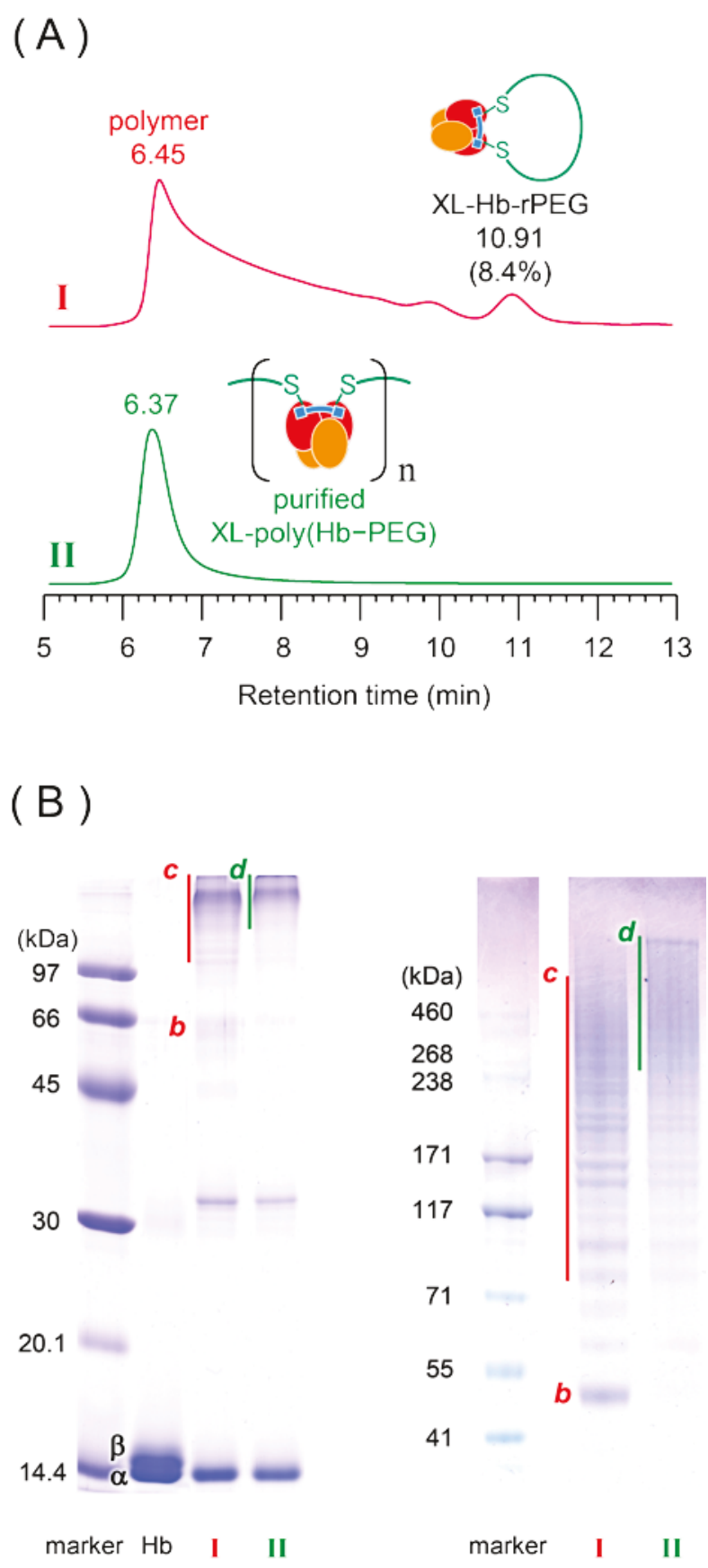

Figure 10. (A) SEC profiles and (B) SDS-PAGE of ring-opened and fixed polymer, XLpoly(Hb-PEG), before (chromatogram I and lane I) and after (chromatogram II and lane II) purification using SEC. In (B), the left panel shows the electrophoretic image conducted in a 
$15 \%$ acrylamide gel. The right panel shows that conducted in a 3-8\% gradient gel. Band $\boldsymbol{b}$ is assigned as $\beta-\beta-$ ringPEG; bands $\boldsymbol{c}$ and bands $\boldsymbol{d}$ are assigned as poly $(\beta-\beta-\mathrm{PEG})$.
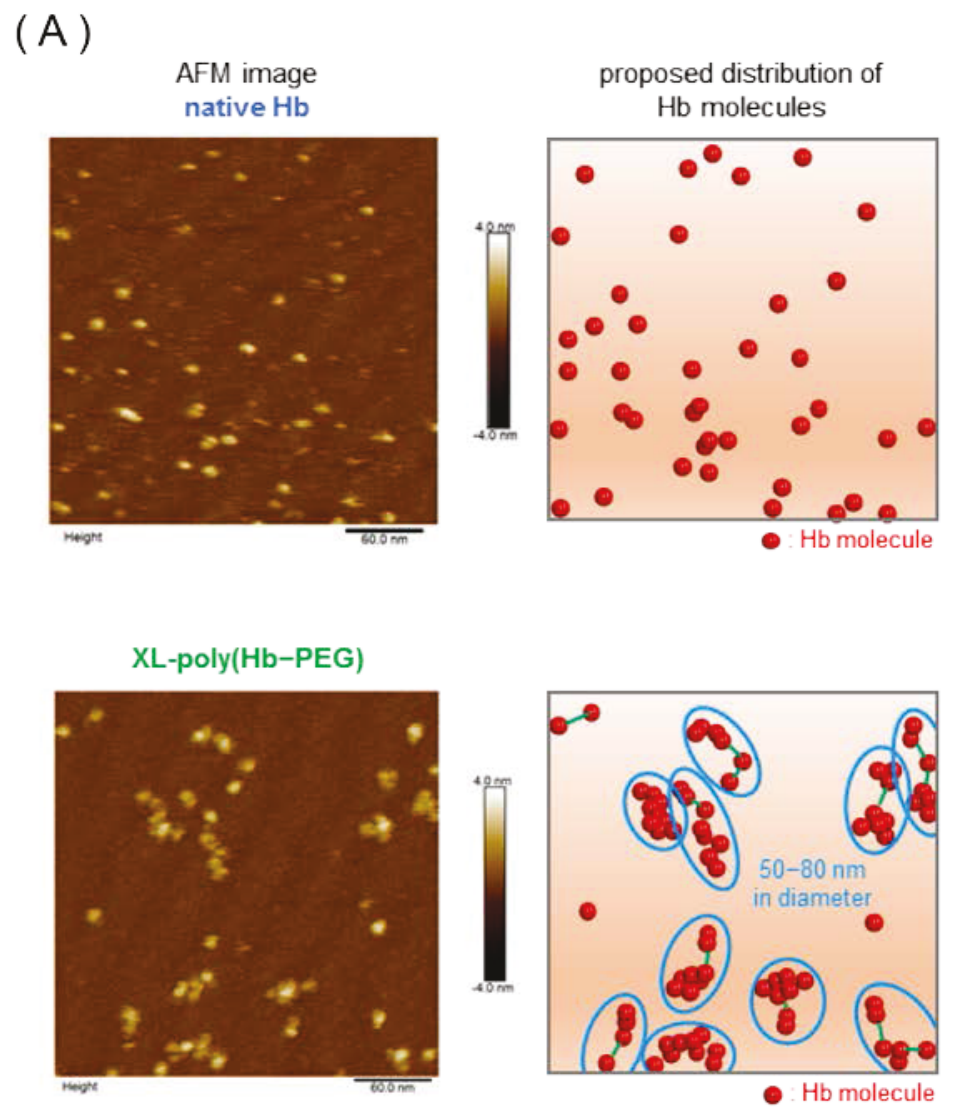

( B )

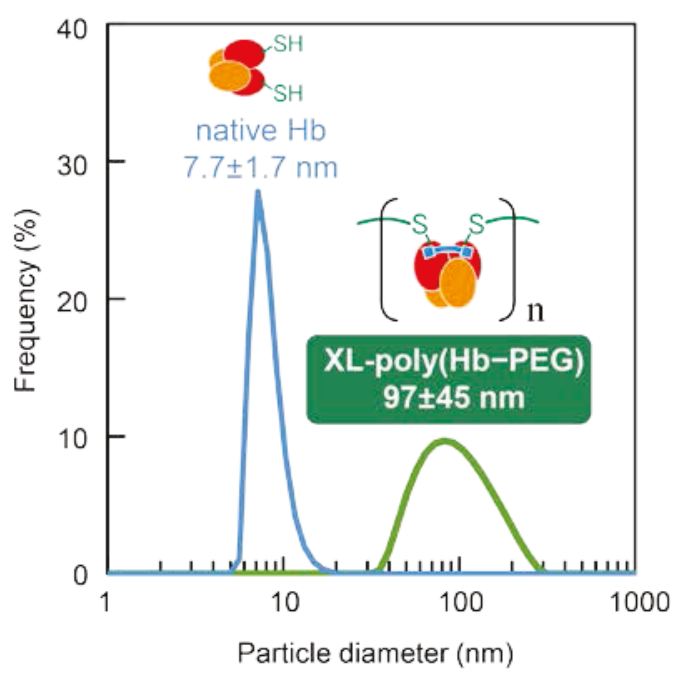


Figure 11. (A) AFM images of native $\mathrm{Hb}$ and the purified $\mathrm{XL}-$ poly $(\mathrm{Hb}-\mathrm{PEG})$ on mica surfaces in distilled water, with schematic illustrations of $\mathrm{Hb}$ molecules inferred from the AFM images. $\mathrm{Hb}$ molecules constituting XL-poly(Hb-PEG) were conjugated to form particles of 50-80 nm diameter. (B) Particle size distributions of native $\mathrm{Hb}$ (blue) and purified XL-poly(Hb-PEG) (green) obtained from DLS measurements. 


\section{DISCUSSION}

As described herein, we developed an efficient polymerization procedure for creating polymerized $\mathrm{Hb}$ using a novel approach: ring-opening polymerization. We synthesized a cyclic $\mathrm{Hb}$-ring monomer with two $\beta$ subunits bound through $10 \mathrm{kDa}$ PEG chain (Hb-rPEG, Figure 1). During the intermolecular subunit exchange of $\alpha \beta$ dimers, Hb-rPEG induces ring-opening polymerization to produce a supramolecular $\mathrm{Hb}$ polymer: poly(Hb-PEG). The ring-closed monomer and the ring-opened polymer were fixed respectively by covalent bonding using DBBF crosslinking to obtain XL-Hb-rPEG and XL-poly(Hb-PEG). This is the first example of an $\mathrm{Hb}$ polymer obtained by ring-opening polymerization and succeeding covalent bonding using sitespecific crosslinking.

The Hb-ring monomer, Hb-rPEG, was synthesized as shown in Figure 1. A similar modification of $\mathrm{Hb}$ was reported by Manjula et al. using a shorter $2 \mathrm{kDa}$ bi-functional maleimide-PEG ( $2 \mathrm{kDa}$ mal 2 -PEG) ${ }^{37}$ Their purpose was to create an intramolecularly $\beta \beta$-PEGcrosslinked-Hb for maintaining allosteric effects of the $\mathrm{Hb}$ tetramer. ${ }^{38}$ As described in their report, two equimolar native $\mathrm{Hb}$ was reacted to $2 \mathrm{kDa}$ mal $_{2}-\mathrm{PEG}$. Once a dumbbell type $\mathrm{Hb}$ dimer $(\mathrm{Hb}-\mathrm{PEG}-\mathrm{Hb})$ is generated, however, it readily transforms to monomeric $\beta \beta$-PEGcrosslinked- $\mathrm{Hb}$ (with similar structure as $\mathrm{Hb}-\mathrm{rPEG}$ ) and native $\mathrm{Hb}$. Consequently, only a trace amount of $\mathrm{Hb}-\mathrm{PEG}-\mathrm{Hb}$ appeared. Acharya et al. reported that a shorter $600 \mathrm{Da} \mathrm{mal}_{2}-\mathrm{PEG}$ tends to generate $\mathrm{Hb}-\mathrm{PEG}-\mathrm{Hb}$ and oligomers through a stepwise reaction, and that of a $2 \mathrm{kDa} \mathrm{mal}_{2}-$ PEG preferentially generates a thermodynamically stable monomeric $\mathrm{Hb}$ with a ring structure because it has suitable length only for intramolecular binding of two $\beta 93$ Cys thiol groups. ${ }^{39}$ 
For the work described in this report, a longer $10 \mathrm{kDa}$ mal $_{2}-\mathrm{PEG}$ was reacted to a slightly excessive amount of native $\mathrm{Hb}$. In the reaction mixture, both $\mathrm{Hb}$-rPEG and dimeric $\mathrm{Hb}-\mathrm{PEG}-$ $\mathrm{Hb}$, and their corresponding oligomers were generated because a longer PEG chain enhances the exchange of $\alpha \beta$ subunits between PEGylated and native Hbs. ${ }^{26}$ The existence of such oligomers was ascertained by DBBF crosslinking of the mixture of $\mathrm{Hb}-\mathrm{rPEG}$ and native $\mathrm{Hb}$ (Figures 7B, 7C, and 7D). We reported recently that PEGylated $\mathrm{Hb}$ is allowed to exchange $\alpha \beta$ subunits with native $\mathrm{Hb} .{ }^{26}$ Based on this insight, $\mathrm{Hb}-\mathrm{PEG}-\mathrm{Hb}$ is transformed continuously to $\mathrm{Hb}-\mathrm{rPEG}$ through equilibrium by removing native $\mathrm{Hb}$ using a salting out technique. The synthesis of $\mathrm{Hb}-$ rPEG and the site-selective PEGylation of two $\beta$ subunits were confirmed using SEC and SDSPAGE (Figure 2).

The molecular weights of Hb-rPEG determined using SEC (98 kDa) and COP (104 kDa) are much larger than expected $(75 \mathrm{kDa})$. Reportedly, conjugated hydrophilic PEG chains expand in an aqueous solution and increase the hydrodynamic volume of PEGylated $\mathrm{Hb} \cdot{ }^{40} \mathrm{COP}(\pi)$ is described as a function of the concentration of $\mathrm{Hb}$ units $(C)$, as shown in Eq. 1. It is converted to the equation of $\pi / C$ as Eq. 2. In general, water-soluble protein shows a linear relation between $\pi / C$ and $C$, as shown in Figure 3B because the third-order and higher-order virial coefficients in Eq. 2 are sufficiently small as to be negligible. ${ }^{32}$ It is noteworthy that the plots of Hb-rPEG show an incontestable parabolic curve (Figure 3B, red line). This result indicates that Hb-rPEG shows inconsistent size at every concentration, and indicates that the third virial coefficient $A_{3}$ is not negligible. Actually, the particle diameter increase and dispersity increase depending on the concentration were observed in the DLS analysis of Hb-rPEG (Figure 4). These results suggest the intermolecular association ascribed to the ring-opening polymerization as shown in Figure 1 at a higher concentration. Actually, Hb-rPEG can be regarded as the two $\alpha \beta$ dimers connected by 
PEG, induced by dissociation of $\alpha_{2} \beta_{2}$ tetrameric structure. The terminal $\alpha \beta$ subunits interact strongly to form a stable $\alpha_{2} \beta_{2}$ tetramer. The interaction functions intramolecularly at a lower concentration, and intermolecularly at a higher concentration. Reportedly, the third virial coefficient is ascribed to interaction among three molecules. ${ }^{41,42}$ The intermolecular association of two $\alpha \beta$ dimers at PEG terminals is inferred to the indispensable third virial coefficient in COP measurements of $\mathrm{Hb}$-rPEG.

Accordingly, Hb-rPEG is regarded as forming a monomeric ring structure by itself. In actuality, it also forms a ring-opened polymeric structure (poly $(\mathrm{Hb}-\mathrm{PEG})$ ), especially at a higher concentration. Such behavior is regarded as a ring-chain mechanism of supramolecular polymerization. ${ }^{43}$ Reportedly, some supramolecular protein polymers are constructed using specific interactions of proteins such as heme-heme pocket interaction, ${ }^{44}$ coiled-coil interaction, ${ }^{45}$ helix bundle folding, ${ }^{46}$ and inter-subunit interaction. ${ }^{47}$ Our ring-opening polymerization technique is the first reported use of the $\alpha_{2} \beta_{2}$ tetrameric structure of $\mathrm{Hb}$ molecule to construct a supramolecular protein polymer.

In the supramolecular polymers, interactions between monomers are reversible. The molecular weight of supramolecular polymer depends on the combination of the monomer concentration and the binding constant. ${ }^{1}$ A few fixation methods have been reported for supramolecular polymers of organic compounds using covalent bonding ${ }^{48,49}$ or mechanical interlocking. ${ }^{50}$ For the present work, the ring-opened and ring-closed structures were fixed by DBBF crosslinking, a site-specific covalent bonding of $\beta$ subunits at a cavity of $\mathrm{Hb}$ molecule (Figure 1). No example of such a fixing strategy of supramolecular protein polymer employing 
site-specific covalent bonding of protein subunits has been described in any report of the relevant literature.

By adding DBBF, Hb-rPEG and poly(Hb-PEG) became the corresponding XL-Hb-rPEG and XL-poly(Hb-PEG) (Figures 5 and 6). The ratios of crosslinked monomer XL-Hb-rPEG, as determined by the peak area in SEC (Figure 5), are regarded as reflecting the ratios of the equilibrated state immediately before adding DBBF. Quantitative analysis was done based on the ratios of monomeric XL-Hb-rPEG at various initial monomer concentrations $[\mathrm{M}]_{0}$ before $\mathrm{DBBF}$ crosslinking. The equilibrium monomer concentration $[\mathrm{M}]_{\mathrm{e}}$ becomes constant at higher $[\mathrm{M}]_{0}$, which is the same behavior as the traditional ring-opening polymerization equilibrium of small cyclic monomers, as represented by lactones. ${ }^{51}$

Equilibrium constant $K$ for Eq. 4 was determined as $5.68 \mathrm{mM}^{-1}$. Moreover, $[\mathrm{M}]_{\mathrm{e}}$ was $0.176 \mathrm{mM}([\mathrm{Hb}]=1.14 \mathrm{~g} / \mathrm{dL})$ at a higher polymerization rate (Figure 9). When $[\mathrm{M}]_{0}$ is lower than asymptotic $[\mathrm{M}]_{\mathrm{e}}$, polymerization is thermodynamically forbidden. ${ }^{52} \mathrm{Hb}$-rPEG cannot be converted into linear macromolecules at a concentration below $[\mathrm{M}]_{\mathrm{e}}(0.176 \mathrm{mM},[\mathrm{Hb}]=1.14$ $\mathrm{g} / \mathrm{dL}$ ), and it starts polymerization above this concentration. Estimated $\overline{\mathrm{DP}}$ increased proportionally with $[\mathrm{M}]_{0}$. The molecular weight ideally reached nearly $1 \mathrm{MDa}(990 \mathrm{kDa})$ at $[\mathrm{M}]_{0}$ $=2.33 \mathrm{mM}([\mathrm{Hb}]=15.0 \mathrm{~g} / \mathrm{dL})$. This result suggests that the higher concentration of Hb-rPEG realizes the higher molecular weight of the ring-opened polymer. However, a limitation of solubility exists, as ascribed to the self-volumes of Hbs and PEG chains. Regarding Hb-rPEG using $10 \mathrm{kDa}$ PEG, it was difficult to raise the $\mathrm{Hb}$ concentration beyond $20 \mathrm{~g} / \mathrm{dL}$. 
The higher molecular weight component of XL-poly(Hb-PEG) was purified and characterized. The molecular weight of purified XL-poly(Hb-PEG) obtained by SEC ( $844 \mathrm{kDa}$, Figure 10A) and that of consisting of polymerized $\beta-\beta$ subunits by SDS-PAGE (around 460 $\mathrm{kDa}$, Figure 10B) show that 11 or more $\mathrm{Hb}$ molecules are conjugated by PEG chains. The number of conjugated $\mathrm{Hb}$ molecules was confirmed directly from the AFM image (Figure 11A).

In the case of glutaraldehyde-polymerized Hbs (poly-Hbs), which are clinically tested HBOCs, the $\overline{\mathrm{DP}}$ is almost $2-4$ and the maximum number of conjugated $\mathrm{Hb}$ units is $6-8 .{ }^{53}$ Reportedly, the molecular size of HBOCs is an important factor preventing adverse effects; small HBOCs would cause vasoconstriction by extravasation and permeation across the endothelial layer. ${ }^{22}$ Our novel strategy of ring-opening polymerization of $\mathrm{Hb}$ realizes higher $\overline{\mathrm{DP}}$ compared with the poly-Hbs, with notably larger particle diameter (97 nm, Figure 11B) than PEGconjugated $\mathrm{Hb}(13$ or $22 \mathrm{~nm}),{ }^{10,17}$ glutaraldehyde-polymerized Hbs $(47 \mathrm{~nm}),{ }^{17}$ zero-linked Hbs $(48 \mathrm{~nm}),{ }^{54}$ and polysaccharide-polymerized $\mathrm{Hbs}(68 \mathrm{~nm}) .{ }^{17}$

To confirm the polymerization mechanism of $\mathrm{Hb}$-rPEG, native $\mathrm{Hb}$ was added as an inhibitor before DBBF crosslinking. Results demonstrate that the products become gradually smaller with increasing amounts of native $\mathrm{Hb}$. Additionally, discontinuous peaks of small oligomers were observed in SEC (Figures 7A-7D), which were identical to oligomeric XLHbs conjugated by mal $_{2}-\mathrm{PEG}$ (Figures $\mathbf{7 F}-\mathbf{7 H}$ ). This result indicates the mechanism clearly. The exchange of $\alpha \beta$ subunits is the trigger of ring-opening polymerization of Hb-rPEG. Moreover, this result indicates that using a chemically modified $\mathrm{Hb}$ bearing a functional group as an inhibitor makes it possible to provide functional groups at the terminals of XL-poly(Hb-PEG). Such terminal-targeted modification would be difficult if using stepwise conjugation of XLHb. 
Equimolar reaction of XLHb and mal 2 -PEG produces linear polymer poly(XLHb) by alternative conjugation of PEGs and XLHbs (Figure 7E). The poly(XLHb) structure is similar or identical to XL-poly(Hb-PEG). Poly(XLHb) is observed at $6.45 \mathrm{~min}$ in SEC, which corresponds to molecular weight greater than $800 \mathrm{kDa}$. However, poly(XLHb) contains unreacted XLHb. Moreover, the amounts of small oligomers were greater than in XL-poly(Hb-PEG) (Figure 7A).

The supramolecular polymer (poly $(\mathrm{Hb}-\mathrm{PEG})$ ) prepared here is regarded as inapplicable for blood substitutes because it would decompose to the monomeric structures by dilution in blood through the dissociation equilibrium of $\alpha_{2} \beta_{2}$ subunits. DBBF crosslinked polymer, XLpoly( $\mathrm{Hb}-\mathrm{PEG})$, is expected to retain the $\alpha_{2} \beta_{2}$ structure, which makes it as an injectable fluid. Visible light absorption spectrometry of XL-poly(Hb-PEG) showed reversible oxygen binding. Its oxygen dissociation curve clarified a higher oxygen affinity (lower $P_{50}$ value, 5.2 Torr) and a smaller Hill number $(n=1.1)$ than those of native $\mathrm{Hb}\left(P_{50}=8.2\right.$ Torr, $\left.n=2.2\right)$ (Supporting information Figure S4). Both PEGylation at $\beta 93 \mathrm{Cys}$ and DBBF crosslinking at $\beta 82 \mathrm{Lys}$ are expected to affect the left shift of the oxygen equilibrium curve. ${ }^{55}$ Reportedly, HBOCs with a high oxygen affinity are effective for targeted oxygen delivery to a hypoxic tissue. ${ }^{56,57}$ Consequently, XL-poly(Hb-PEG) will eventually be applicable as other HBOCs with high oxygen affinity for such clinical use.

For other supramolecular protein polymers, multi-level architectures such as microtube, ${ }^{58}$ nanolayer, ${ }^{59}$ nanoparticle, and other three-dimensional structures ${ }^{60}$ are constructed by the combination of self-assembling proteins and artificial scaffolds. Our novel strategy is expected to be applicable not only for providing a simple linear $\mathrm{Hb}$ polymer but also for constructing other highly ordered $\mathrm{Hb}$ architectures. 


\section{CONCLUSION}

In this work, we achieved ring-opening polymerization of $\mathrm{Hb}$ triggered by intermolecular subunit exchange of $\alpha \beta$ dimers. The ring-opened polymer was fixed by covalent bonding with intramolecular crosslinking of two $\beta$ subunits. Analyses of the obtained polymer clarified that ring-opening polymerization provides greater benefits for efficiency $(\overline{\mathrm{DP}}=13.2$ on the average, $M_{\mathrm{n}}=990 \mathrm{kDa}$ ) compared with random polymerization of $\mathrm{Hb}$ using glutaraldehyde. Additionally, the amount of lower molecular weight components was found to be smaller than the stepwise conjugation of XLHb. This is the first example of ring-opening polymerization using the association-dissociation equilibrium of $\alpha_{2} \beta_{2}$ subunits in an $\mathrm{Hb}$ molecule $\left(\alpha_{2} \beta_{2} \rightleftarrows 2 \alpha \beta\right)$, and of covalent bonding of the supramolecular $\mathrm{Hb}$ polymer using site-specific $\mathrm{Hb}$ modification. The technique is expected to be applicable not only for providing a simple linear $\mathrm{Hb}$ polymer but also for constructing other highly ordered $\mathrm{Hb}$ architectures, which are expected to realize highly aligned and efficiently polymerized Hbs.

\section{ASSOCIATED CONTENTS:}

Supporting Information

The supporting information contains the detailed information of COP, DLS, SEC, and AFM; Oxygen equilibrium curve measurement (PDF).

\section{AUTHOR INFORMATION:}

Corresponding Author 
*E-mail: hirosakai@naramed-u.ac.jp

ORCID

Takashi Matsuhira: 0000-0003-2429-9847

Hiromi Sakai: 0000-0002-0681-3032

Author Contributions

T.M., K.Y., and H.S. conceived the study and designed the experiments. T.M. performed experiments and data analyses. T.M. and H.S. wrote the manuscript. All authors have given their approval to the final version of the manuscript.

Notes

The authors declare no competing financial interest.

\section{ACKNOWLEDGMENTS}

This research was supported by a Grant-in-Aid for Scientific Research (Kiban C, No. 17K01367) from the Japan Society for the Promotion of Sciences (JSPS). The authors acknowledge Otsuka Electronics Co. Ltd. for technical assistance with measurement using an ELSZ-2000ZS particle analyzer.

\section{REFERENCES}

(1) Yang, L.; Tan, X.; Wang, Z.; Zhang, X. Chem. Rev. 2015, 115, 7196-7239. 
(2) Luo, Q.; Dong, Z.; Hou, C.; Liu, J. Chem. Commun. 2014, 50, 9997-10007.

(3) Chang, T. M. Nat. Rev. Drug Discov. 2005, 4, 221-235.

(4) Savitsky, J. P.; Doczi, J.; Black, J.; Arnold, J. D. Clin. Pharmacol. Ther. 1978, 23, 73-80.

(5) Yu, B. L.; Shahid, M.; Egorina, E. M.; Sovershaev, M. A.; Raher, M. J.; Lei, C.; Wu, M. X.; Bloch, K. D.; Zapol, W. M. Anesthesiology 2010, 112, 586-594.

(6) Highsmith, F. A.; Driscoll, C. M.; Chung, B. C.; Chavez, M. D.; Macdonald, V. W.; Manning, J. M.; Lippert, L. E.; Berger, R. L.; Hess, J. R. Biologicals 1997, 25, 257-268.

(7) Walder, J. A.; Walder, R. Y.; Arnone, A. J. Mol. Biol. 1980, 141, 195-216.

(8) Alagic, A.; Koprianiuk, A.; Kluger, R. J. Am. Chem. Soc. 2005, 127, 8036-8043.

(9) Meng, F.; Kassa, T.; Jana, S.; Wood, F.; Zhang, X.; Jia, Y.; D'Agnillo, F.; Alayash, A. I. Bioconjug. Chem. 2018, 29, 1560-1575.

(10)Manjula, B. N.; Tsai, A. G.; Intaglietta, M.; Tsai, C. H.; Ho, C.; Smith, P. K.;

Perumalsamy, K.; Kanika, N. D.; Friedman, J. M.; Acharya, S. A. Protein J. 2005, 24, $133-146$.

(11)Misra, H.; Lickliter, J.; Kazo, F.; Abuchowski, A. Artif. Organs 2014, 38, 702-707.

(12)Hu, T.; Su, Z. J. Biotechnol. 2003, 100, 267-275.

(13)Xiong, Y.; Steffen, A.; Andreas, K.; Müller, S.; Sternberg, N.; Georgieva, R.; Bäumler, H. Biomacromolecules 2012, 13, 3292-3300.

(14)Kluger, R.; Zhang, J. J. Am. Chem. Soc. 2003, 125, 6070-6071. 
(15)Hai, T. T.; Pereira, D. E.; Nelson, D. J.; Srnak, A.; Catarello, J. Bioconjug. Chem. 1999, 10, 1013-1020.

(16)Boykins, R. A.; Buehler, P. W.; Jia, Y.; Venable, R.; Alayash, A. I. Proteins 2005, 59, $840-855$.

(17)Sakai, H.; Yuasa, M.; Onuma, H.; Takeoka, S.; Tsuchida, E. Bioconjug. Chem. 2000, 11, 56-64.

(18)Kluger, R.; O'Brien, J. L.; Teytelboym, A. J. Am. Chem. Soc. 1999, 121, 6780-6785.

(19)Gourianov, N.; Kluger, R. J. Am. Chem. Soc. 2003, 125, 10885-10892.

(20)Buehler, P. W.; Boykins, R. A.; Norris, S.; Alayash, A. I. Anal. Chem. 2006, 78, 4634-4641.

(21)Modery-Pawlowski, C. L.; Tian, L. L.; Pan, V.; Sen Gupta, A. Biomacromolecules 2013, 14, 939-948.

(22)Sakai, H.; Hara, H.; Yuasa, M.; Tsai, A. G.; Takeoka, S.; Tsuchida, E.; Intaglietta, M. Am. J. Physiol. Heart Circ. Physiol. 2000, 279, H908-15.

(23)Wollocko, H.; Wollocko, B. M.; Wollocko, J.; Grzegorzewski, W.; Smyk, L. Artif. Cells Nanomed. Biotechnol. 2017, 45, 1350-1355.

(24)Arifin, D. R.; Palmer, A. F. Biomacromolecules 2005, 6, 2172-2181.

(25)Sakai, H.; Sato, A.; Takeoka, S.; Tsuchida, E. Biomacromolecules 2009, 10, 2344-2350. 
(26)Matsuhira, T.; Kure, T.; Yamamoto, K.; Sakai, H. Biomacromolecules 2018, 19, $3412-3420$.

(27)Manjula, B. N.; Tsai, A.; Upadhya, R.; Perumalsamy, K.; Smith, P. K.; Malavalli, A.; Vandegriff, K.; Winslow, R. M.; Intaglietta, M.; Prabhakaran, M.; Friedman, J. M.; Acharya, S. A. Bioconjug. Chem. 2003, 14, 464-472.

(28)Fernandez, E. J.; Abad-Zapatero, C.; Olsen, K. W. J. Mol. Biol. 2000, 296, 1245-1256.

(29)Sakai, H.; Sou, K.; Tsuchida, E. Methods Enzymol. 2009, 465, 363-384.

(30)White, F. L.; Olsen, K. W. Arch. Biochem. Biophys. 1987, 258, 51-57.

(31)Osaki, S.; Yamamoto, K.; Matsuhira, T; Sakai, H. Polym. J. 2016, 48, 659-663.

(32)Vandegriff, K. D.; McCarthy, M.; Rohlfs, R. J.; Winslow, R. M. Biophys. Chem. 1997, 69, $23-30$.

(33)Tomita, D.; Kimura, T.; Hosaka, H.; Daijima, Y.; Haruki, R.; Ludwig, K.; Böttcher, C.; Komatsu, T. Biomacromolecules 2013, 14, 1816-1825.

(34) Styslinger, T. J.; Zhang, N.; Bhatt, V. S.; Pettit, N.; Palmer, A. F.; Wang, P. G. J. Am. Chem. Soc. 2012, 134, 7507-7515.

(35)McGrath, J. E. Chapter 1, in Ring-Opening Polymerization, Kinetics, Mechanisms, and Synthesis; McGrath, J. E. Ed.; American Chemical Society, Washington, D.C.: 1985; pp $1-22$.

(36)Stille, J. K. J. Chem. Educ. 1981, 58, 682-686. 
(37)Manjula, B. N.; Malavalli, A.; Smith, P. K.; Chan, N. L.; Arnone, A.; Friedman, J. M.; Acharya, S. A. J. Biol. Chem. 2000, 275, 5527-5534.

(38)Hu, T.; Manjula, B. N.; Li, D.; Brenowitz, M.; Acharya, S. A. Biochem. J. 2007, 402, 143151.

(39)Acharya, S. A.; Intaglietta, M.; Tsai, A. G.; Meng, F. In Hemoglobin-Based Oxygen Carriers as Red Cell Substitutes and Oxygen Therapeutics; Kim, H. W., Greenburg, A. G., Eds.; Springer-Verlag: Berlin, 2013; pp 185-234.

(40)Li, D.; Manjula, B. N.; Acharya, S. A. Protein J. 2006, 25, 263-274.

(41)Nishi, Y.; Nakamura, Y.; Norisue, T. Polym. J. 2009, 41, 58-62.

(42)Yamakawa, H.; Abe, F.; Einaga, Y. Macromolecules 1994, 27, 3272-3275.

(43)De Greef, T. F.; Smulders, M. M.; Wolffs, M.; Schenning, A. P.; Sijbesma, R. P.; Meijer, E. W. Chem. Rev. 2009, 109(11), 5687-5754.

(44)Kitagishi, H.; Oohora, K.; Yamaguchi, H.; Sato, H.; Matsuo, T.; Harada, A.; Hayashi, T. J. Am. Chem. Soc. 2007, 129, 10326-10327.

(45)Staples, J. K.; Oshabena, K. M.; Horne, W. S. Chem. Sci. 2012, 3, 3387-3392.

(46)Kobayashi, N.; Inano, K.; Sasahara, K.; Sato, T.; Miyazawa, K.; Fukuma, T.; Hecht, M. H.; Song, C.; Murata, K.; Arai, R. ACS Synth. Biol. 2018, 7(5), 1381-1394.

(47)Bastings, M. M. C.; De Greef, T. F. A.; Van Dongen, J. L. J.; Merkxb, M.; Meijer, E. W. Chem. Sci. 2010, 1, 79-88. 
(48)Monemian, S.; Jang, K. S.; Ghassemi, H.; Korley, L. T. J. Macromolecules 2014, 47 (16), $5633-5642$.

(49)Tezuka, Y. Chapter 13, in Supramolecular Polymer Chemistry; Harada, A. Ed.; WileyVCH Verlag: 2012; pp 293-303.

(50)Miyawaki, A.; Miyauchi, M.; Takashima, Y.; Yamaguchi, H.; Harada, A. Chem. Commun. 2008, 4, 456-458.

(51)Martello, M. T.; Burns, A.; Hillmyer, M. ACS Macro Lett. 2012, 1, 131-135.

(52)Slomkowski, S.; Duda, A. In Ring-Opening Polymerization; Brunelle, D. J. Ed.; Carl Hanser Verlag: 1993; pp 87-128.

(53)Day, T. K. J. Vet. Emerg. Crit. Care 2003, 13, 77-93.

(54)Matheson, B.; Kwansa, H. E.; Bucci, E.; Rebel, A.; Koehler, R. C. J. Appl. Physiol. 2002, 93, 1479-1486.

(55) Vandegriff, K. D.; Malavalli, A.; Olsen, S. D. Diaspirin crosslinked PEGylated hemoglobin. U. S. Patent 10,029,001 B2, Jul. 24, 2018.

(56)Tsai, A. G.; Vandegriff, K. D.; Intaglietta, M.; Winslow, R. M. Am. J. Physiol. Heart Circ. Physiol. 2003, H1411-1419.

(57)Sakai, H.; Tsuchida, E. J. Liposome Res. 2007, 17, 227-235.

(58)Yang, G.; Kochovski, Z.; Ji, Z.; Lu, Y.; Chen, G.; Jiang, M. Chem. Commun. 2016, 52, 9687-9690. 
(59)Yang, G.; Zhang, X.; Kochovski, Z.; Zhang, Y.; Dai, B.; Sakai, F.; Jiang, L.; Lu, Y.;

Ballauff, M.; Li, X.; Liu, C.; Chen, G.; Jiang, M. J. Am. Chem. Soc. 2016, 138, $1932-1937$.

(60)Yang, L.; Liu, A.; Cao, S.; Putri, R. M.; Jonkheijm, P.; Cornelissen J. J. L. M. Chem. Eur. J. 2016, 22, 15570-15582. 
Table of contents (TOC) graphic

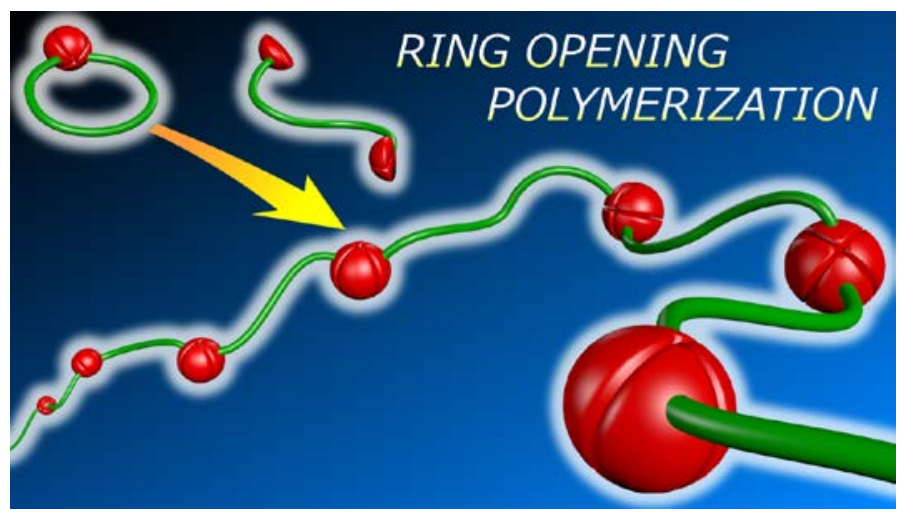

